\title{
The ADP receptor P2RY12 regulates osteoclast function and pathologic bone remodeling
}

\author{
Xinming Su, ${ }^{1}$ Desiree H. Floyd, ${ }^{1}$ Alun Hughes, ${ }^{2}$ Jingyu Xiang, ${ }^{1}$ Jochen G. Schneider, ${ }^{1,3,4}$ \\ Ozge Uluckan, ${ }^{1}$ Emanuela Heller, ${ }^{1}$ Hongju Deng, ${ }^{1}$ Wei Zou, ${ }^{5}$ Clarissa S. Craft, ${ }^{6}$ Kaiming Wu, ${ }^{1}$ \\ Angela C. Hirbe, ${ }^{1}$ Dorota Grabowska, ${ }^{7}$ Mark C. Eagleton, ${ }^{1}$ Sarah Townsley, ${ }^{1}$ Lynne Collins, ${ }^{7}$ \\ David Piwnica-Worms, 6,7 Thomas H. Steinberg, 7 Deborah V. Novack, ${ }^{5}$ Pamela B. Conley, ${ }^{8}$ \\ Michelle A. Hurchla, ${ }^{1}$ Michael Rogers, ${ }^{2}$ and Katherine N. Weilbaecher ${ }^{1}$
}

\begin{abstract}
${ }^{1}$ Department of Medicine, Division of Oncology, Washington University in St. Louis School of Medicine, St. Louis, Missouri, USA.
${ }^{2}$ Musculoskeletal Research Programme, School of Medicine and Dentistry, Institute of Medical Sciences, University of Aberdeen, Foresterhill, Aberdeen, Scotland. ${ }^{3}$ Luxembourg Centre for Systems Biomedicine (LCSB), University of Luxembourg, Luxembourg. ${ }^{4}$ Saarland University Medical Center, Internal Medicine II, Homburg/Saar, Germany. ${ }^{5}$ Department of Medicine, Division of Bone and Mineral Diseases, ${ }^{6}$ Department of Cell Biology and Physiology, and ${ }^{7}$ BRIGHT Institute, Washington University in St. Louis School of Medicine, and St. Louis VA Medical Center, St. Louis, Missouri, USA. ${ }^{8}$ Portola Pharmaceuticals Inc., South San Francisco, California, USA.
\end{abstract}

\begin{abstract}
The adenosine diphosphate (ADP) receptor P2RY12 (purinergic receptor P2Y, G protein coupled, 12) plays a critical role in platelet aggregation, and P2RY12 inhibitors are used clinically to prevent cardiac and cerebral thrombotic events. Extracellular ADP has also been shown to increase osteoclast (OC) activity, but the role of P2RY12 in OC biology is unknown. Here, we examined the role of mouse P2RY12 in OC function. Mice lacking $P 2 r y 12$ had decreased OC activity and were partially protected from age-associated bone loss. P2ry12 ${ }^{-/-}$OCs exhibited intact differentiation markers, but diminished resorptive function. Extracellular ADP enhanced OC adhesion and resorptive activity of WT, but not P2ry12-/-, OCs. In platelets, ADP stimulation of P2RY12 resulted in GTPase Ras-related protein (RAP1) activation and subsequent $\alpha_{\mathrm{IIb}} \beta_{3}$ integrin activation. Likewise, we found that ADP stimulation induced RAP1 activation in WT and integrin $\beta_{3}$ gene knockout (Itgb3 $\left.3^{-/}\right)$OCs, but its effects were substantially blunted in $P 2 r y 12^{-/-}$OCs. In vivo, $P 2 r y 12^{-/-}$mice were partially protected from pathologic bone loss associated with serum transfer arthritis, tumor growth in bone, and ovariectomy-induced osteoporosis: all conditions associated with increased extracellular ADP. Finally, mice treated with the clinical inhibitor of P2RY12, clopidogrel, were protected from pathologic osteolysis. These results demonstrate that P2RY12 is the primary ADP receptor in OCs and suggest that P2RY12 inhibition is a potential therapeutic target for pathologic bone loss.
\end{abstract}

\section{Introduction}

Osteoclasts (OCs) are multinucleated myeloid lineage cells that are the principal source of bone resorptive activity (1). Enhanced OC activity, bone loss, and fractures are associated with rheumatoid arthritis, postmenopausal osteoporosis, and bone metastases (2). Modulation of osteoclastic bone resorption represents an attractive point of therapeutic intervention for the treatment of such conditions.

Numerous purinergic G-protein-coupled nucleotide receptors are expressed in the bone microenvironment $(3,4)$. For example, uridine diphosphate-activated (UDP-activated) P2Y6 has been reported to increase NF- $\mathrm{\kappa B}$ activation and OC survival (5), while P2Y2 (an ATP receptor) expression on osteoblasts (OBs) blocks bone mineralization $(6,7)$. Hoebertz et al. demonstrated that extracellular adenosine diphosphate (ADP) stimulates OC bone resorption in vitro, in part through the $\mathrm{ADP}$ receptor $\mathrm{P} 2 \mathrm{Y} 1$ on OC (8); however, other ADP receptors, including purinergic receptor P2Y, G protein coupled, 12 (P2RY12), which is the target of the widely prescribed antiplatelet drug clopidogrel (Plavix), have not been evaluated for their roles in osteoclastic bone resorption.

Authorship note: Xinming Su and Desiree H. Floyd contributed equally to this work. Conflict of interest: The authors have declared that no conflict of interest exists. Citation for this article: JClin Invest. 2012;122(10):3579-3592. doi:10.1172/JCI38576.
P2RY12, initially identified as the $G \alpha_{i}$-coupled ADP receptor on platelets (9), plays a critical role in thrombus stability in vivo (10). The active metabolite of clopidogrel directly binds and irreversibly inhibits P2RY12 signaling, resulting in diminished platelet activation and aggregation, due in large part to reduced insideout activation of the critical platelet integrin $\alpha_{\mathrm{II}} \beta_{3}(11)$. Mice with targeted disruption of the P2ry 12 gene $\left(P 2 r y 12^{--}\right)$have prolonged bleeding times associated with a decrease in platelet function (9, 10). P2RY12 signaling via $G \alpha_{i}$ results in Ras-related protein (RAP1) GTPase-mediated activation of $\alpha_{\text {IIb }} \beta_{3}$, which is required for platelet activation and aggregation $(9,12-17)$. RAP1 GTPase-mediated activation of $\beta_{3}$-containing integrins has been shown to be necessary for cell adhesion, spreading, and migration (13, 18-20). Importantly, $\beta_{3}$ integrins also play critical roles in OC formation, adhesion, and bone resorption (21). We hypothesized that ADP ligation of P2RY12 would affect OC function in part through activation of $\alpha_{v} \beta_{3}$ integrin (22-25).

P2RY12 has been shown to be biologically important in microglial cells, vascular smooth muscle cells, and brain endothelial cells (26-28) as well as in the growth of tumor cell lines $(29,30)$. P2RY12 is not expressed in splenic macrophages or in human alveolar macrophages and is expressed at negligible or very low levels in most other tissues $(9,31-33)$. Extracellular nucleotides such as 
$\mathrm{ADP} / \mathrm{ATP}$ are released during tissue injury, inflammation, tumor growth, and aging (34-38). ADP released during neuronal injury induces the P2RY12-dependent chemotaxis of microglia to the injury site, allowing for neuroprotective activity $(31,39,40)$. We sought to examine the role of P2RY12 within the bone microenvironment during pathologic conditions associated with increases in extracellular ADP/ATP $(36,41-43)$.

We found that $P 2 r y 12^{-1-}$ mice exhibited decreased OC activity in vivo and were partially protected from aging-related bone loss. $P 2 r y 12^{-/-}$macrophages displayed reduced bone resorptive activity in response to extracellular ADP. Furthermore, extracellular ADP induced RAP1 activation in a P2RY12-dependent manner. Finally, genetic or pharmacologic inhibition of P2RY12 partially protected mice from bone loss associated with arthritis, tumor growth in bone, and estrogen loss. These data suggest that antagonism of P2RY12 was sufficient to decrease OC function in vivo and decrease pathologic bone loss.

\section{Results}

P2ry $12^{-/-}$mice were protected from age-associated bone loss. Under nonpathologic conditions, young mice (aged 2 months) with germline loss of the ADP receptor P2RY12 (P2ry12 $\left.2^{-/}\right)$had no significant changes in bone mineral density (BMD), trabecular bone volume (BV/TV; Supplemental Figure 1, A-C; supplemental material available online with this article; doi:10.1172/JCI38576DS1), trabecular bone formation rate (BFR) (Supplemental Figure 1, F-H), or OC or OB numbers (Supplemental Figure 1, I-M and Supplemental Methods) compared with WT littermates. In contrast, 8-month-old P2ry12-/- mice showed significantly increased BV/ $\mathrm{TV}$ and $\mathrm{BMD}$ in the primary and secondary spongiosa of the tibia compared with WT littermate controls (Figure 1, A-C). Notably, P2ry12 $2^{-/-}$mice displayed trabecular bone extending into the diaphysis. Histological analyses of tibiae showed a decreased OC surface per bone surface in P2ry $12^{-/-}$mice, but no detectable change in OB number, OB surface per bone surface (Figure 1, I-M), or BFR, suggesting that decreased bone resorption predominantly contributed to the increased bone density in older P2ry $12^{-/-}$mice.

Bone turnover markers in 2- and 8-month-old mice were evaluated. In 2-month-old mice, both serum carboxy-terminal collagen crosslinks (CTX) (a marker of OC resorption) and serum $\mathrm{N}$-terminal propeptide of type I procollagen (P1NP) (a marker of bone formation) were significantly decreased in P2ry $12^{-/-}$mice (Supplemental Figure 1, D and E) despite no significant difference in $\mathrm{BV} /$ $\mathrm{TV}$, suggesting that both potential effects of P2RY12 disruption on bone resorption and formation were balanced and resulted in no significant net change in bone volume. At the 8-month time point, serum CTX was significantly decreased in $\mathrm{P} 2 \mathrm{ry} 12^{-/-}$(Figure 1D), while serum P1NP was equivalent to that of WT littermates (Figure 1, E-H), consistent with the findings of increased BV/TV in P2ry $12^{-/-}$mice without significant differences in BFR. CTX and $\mathrm{P} 1 \mathrm{NP}$ levels reflect the bone resorption and formation activities happening at a discrete point in time and may reflect transient effects of P2RY12 on both OC and on OB, whereas BV/TV by $\mu$ CT demonstrates cumulative effects on total bone, which point to defective bone resorption as a predominant consequence of P2ry 12 disruption in 8-month-old mice.

$A D P$ enhanced ex vivo $O C$ bone resorption primarily through the $P 2 R Y 12$ receptor. As P2ry $12^{-/-}$mice exhibited decreased OC activity in vivo (Figure 1, D and M), cell autonomous P2RY12 expression and function were evaluated during osteoclastogenesis.
Expression of P2ry12 increased during ex vivo differentiation from BM macrophages (BMMs) (day 0) to Tartrate-resistant acid phosphatase-positive (TRAP ${ }^{+}$) OCs (day 3 ) and remained higher than BMMs in mature multinucleated OCs (day 5) (Figure 2A). Immunofluorescence confirmed that WT, but not P2ry $12^{-/-}$, OC cultures expressed P2RY12 (Supplemental Figure 2A). Furthermore, WT cells responded to ADP with a decrease in intracellular cAMP (Supplemental Figure 2B), but P2ry12 $2^{-/-}$cells or cells treated with P2RY12 inhibitor did not respond (Supplemental Figure 2, $\mathrm{B}$ and $\mathrm{C}$, and Supplemental Methods). Under standard culture conditions, without ADP stimulation, P2ry $12^{-/-}$BMMs differentiated into multinucleated TRAP-positive OCs (Figure 2B), and no significant differences compared with WT cells in OC differentiation markers on days 1-5 (Figure 2, C-E, Supplemental Figure 3, and Supplemental Methods; all primers are listed in Supplemental Table 1), macrophage proliferation, or OC apoptosis (data not shown) were observed. Functionally, P2ry $12^{-/-}$cells exhibited decreased formation of bone resorption pits compared with WT cells (Figure 2, H-J). ADP stimulation resulted in increases in day 3 OC number and day 6 bone pit area in WT, but not P2ry $12^{-1-}$, OCs (Figure 2, F-J). We performed these experiments using BMMs from 2- and 8-month-old mice and obtained similar results. Because ADP binds both P2Y1 and P2RY12 with high efficiency and potency, with $\mathrm{EC}_{50}$ values in platelet assays of $1 \mu \mathrm{M}$ and $60 \mathrm{nM}$, respectively $(9,44)$, we determine whether P2Y1 could compensate for the loss of P2RY12 expression in OCs. Expression of P2Y1 was not different between WT and P2ry12 $12^{-/-}$cells and was not significantly induced during OC differentiation (Supplemental Figure 4A). In both WT and P2ry $1^{-/-}$cells, ADP stimulation increased actin ring and resorption pit formation on bone (Supplemental Figure 4, B-G), suggesting that ADP signaling through P2Y1 did not exert a significant effect on OC function and that P2RY12 is a major ADP receptor in OCs. These results demonstrate that $P 2 r y 12^{-/-}$cells exhibited intact OC differentiation, but decreased resorptive function, and that extracellular ADP can enhance osteoclastogenesis and OC function primarily through P2RY12.

$P 2 r y 12^{-1-}$ OCs showed impaired ADP-mediated actin ring responses and RAP1 activation. In platelets, ADP stimulation through the P2RY12 receptor acts upstream of the integrin $\alpha_{I I b} \beta_{3}$, resulting in platelet adhesion and aggregation $(9,44-46)$. Because OC adhesion via $\alpha_{v} \beta_{3}$ integrin and other integrins is necessary for actin ring formation and bone resorption (47), we hypothesized that P2RY12 ligation will act upstream of $\alpha_{v} \beta_{3}$, resulting in enhanced $\mathrm{OC}$ actin ring formation. ADP enhanced actin ring formation on bone in WT, but not P2ry12-/-, cells (Figure 3, A and B). These results suggest that extracellular ADP and P2RY12 signaling can modulate actin ring response to extracellular ADP in OCs.

RAP1 GTPase in platelets is activated downstream of P2RY12mediated activation of G $\beta \gamma$ and PI3K and is critical for inside-out activation of platelet integrin $\alpha_{\mathrm{II}} \beta_{3}(14,17,48,49)$. RAP1 also affects the activation of the related integrin $\alpha_{v} \beta_{3}$ in metastatic melanoma cells (50). We found that extracellular ADP resulted in a potent induction of activated GTP-bound RAP1 in WT preOCs that was blunted in P2ry12-/- cells (Figure 3, C and D). ADPmediated RAP1 activation was intact in integrin $\beta_{3}$ gene knockout $\left(\right.$ Itgb $\left.^{-/-}\right)$pre-OCs (Figure 3, C and D), suggesting that P2RY12 is upstream of $\beta_{3}$ integrin signaling in pre-OCs as it is in platelets. The ADP-mediated RAP1 activation in pre-OC was blocked by PI3K inhibitors (wortmannin or LY294002), but not by chelation of cal- 
A

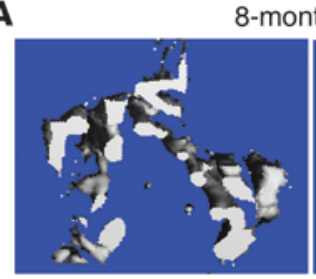

WT

E

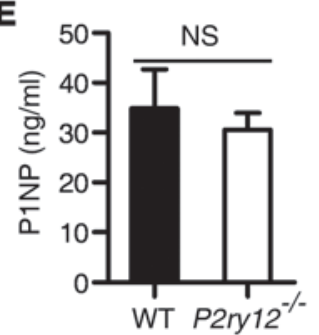

I

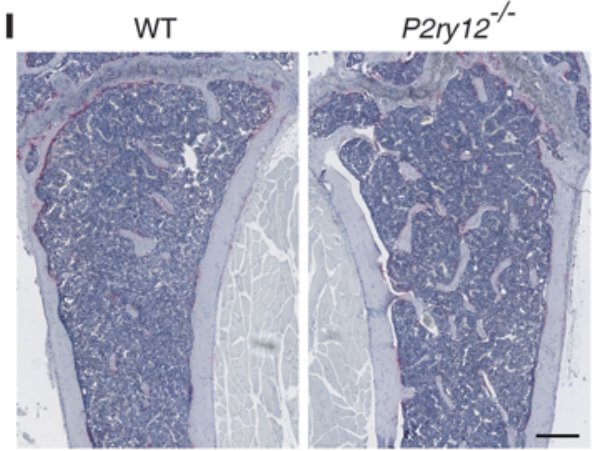

$\mathbf{F}$

WT
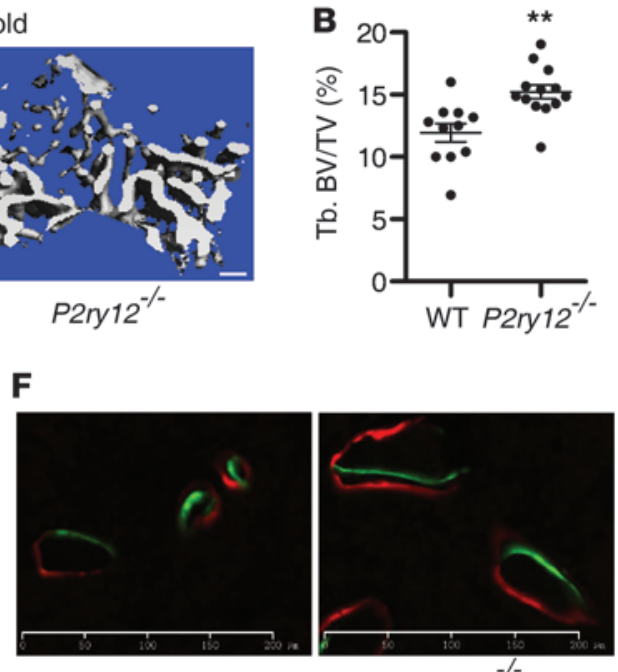

P $2 r y 12^{-/-}$

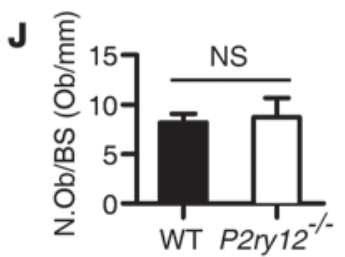

$\mathbf{L}$

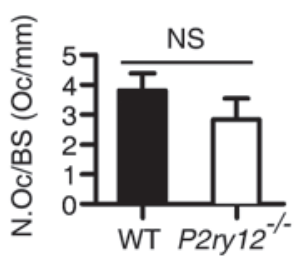

C

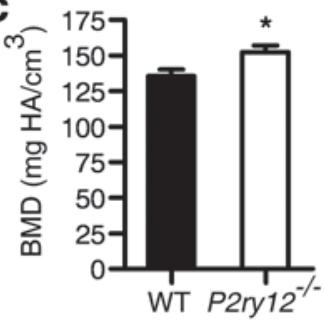

G

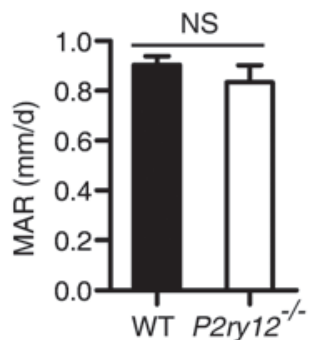

H

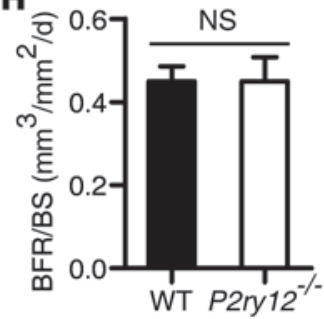

K

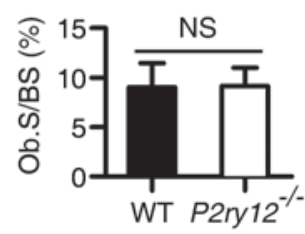

M

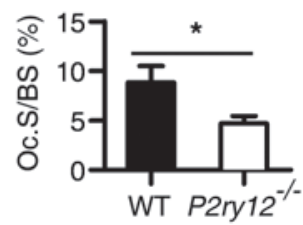

Figure 1

$P 2 r y 12^{-1-}$ mice were protected from age-associated bone loss. (A-C) The primary and secondary spongiosa of the tibias of age- and sex-matched WT and $P 2 r y 12^{-/-}$littermate mice were analyzed by $\mu$ CT scanning. (A) Representative 3D reconstructions of trabecular bone. Scale bar: $200 \mu \mathrm{m}$. (B) Calculation of BV/TV and (C) BMD. Tb, trabecular bone. (D and E) Serum concentration of CTX and P1NP measured by ELISA. (F) Bone formation was visualized by calcein (first) and alizarin red (second) double-labeling and visualized in the trabecular bone. Scale bars: $200 \mu \mathrm{m}$. MAR and BFR are shown (G and $\mathbf{H})$. Bone histology, representative TRAP staining (I). Scale bar: $300 \mu \mathrm{m}$. (J-M) Quantification of OB and OC cells in the primary and secondary spongiosa of the femur. OC number and OC surface per bone surface, OB number and OB surface per bone surface are shown. Data represent mean \pm SD. $n=6$. ${ }^{*} P<0.05 ;{ }^{* \star} P<0.01 ;{ }^{* *} P<0.001$.

cium or inhibitors of adenylate cyclase or PKA (Figure 3E). Furthermore, the absence of P2RY12 did not result in significant differences in the mRNA expression of RAP1 isoforms, RAP1 guanine nucleotide exchange factors (GEFs), or GTPase-activating proteins (GAPs) during OC differentiation (Supplemental Figure 6). These data suggest that the decreased RAP1 activity in $\mathrm{P} 2 r y 12^{-/-}$pre-OCs was likely due to lack of signaling via P2RY12 rather than changes in the expression of genes encoding RAP1 regulatory factors.

Because M-CSF can induce PI3K activation and can rescue the adhesion/spreading defect in $\beta_{3}$ integrin-deficient OCs (51) and can enhance OC survival (52), we evaluated M-CSF induction of RAP1 activation in both $P 2 r y 12^{-/-}$and $\beta_{3}$ integrin-null cells. Treatment of pre-OCs with M-CSF resulted in a rapid and sustained increase in RAP1 activation that was similar in WT and $\mathrm{Itgb3}^{-/}$preOCs, but was delayed in P2ry $12^{-/-}$cells (Supplemental Figure 5, A and B). ADP or M-CSF also activated RAP1 in human OCs generated from peripheral blood mononuclear cells (data not shown). In agreement with ADP treatment (Figure 3, C-E), M-CSF-mediated RAP1 activation in pre-OCs was decreased by inhibitors of PI3K, but not by inhibitors of adenylate cyclase or PKA or by chelation of calcium (Supplemental Figure 5C). These data demonstrate that ADP- and M-CSF-mediated RAP1 activation is downstream of PI3K and may be mediated in part through P2RY12 signaling in OCs. Taken together, these results show that the P2RY12 receptor was an upstream regulator for activation of RAP 1 in pre-OCs.

P2ry $12^{-/-}$mice had decreased arthritis-associated bone loss. Serum transfer arthritis (STA) is a well-characterized model of inflammatory bone loss that phenocopies the osteolysis associated with rheumatoid arthritis (53). In STA, serum from arthritic K/BxN mice, which contain high levels of antibodies against the self antigen glucose-6-phosphate isomerase, is injected intraperitoneally into naive mice, causing joint-centered inflammation and local OC-mediated bone erosion. WT and P2ry $12^{-/-}$mice exhibited similar clinical inflammatory responses, as measured by paw and 
A

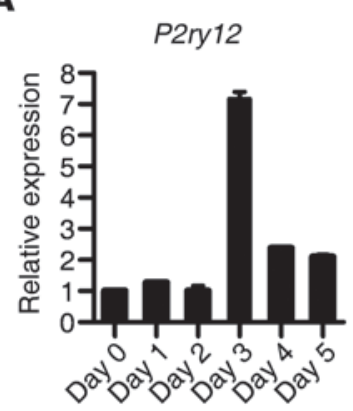

B

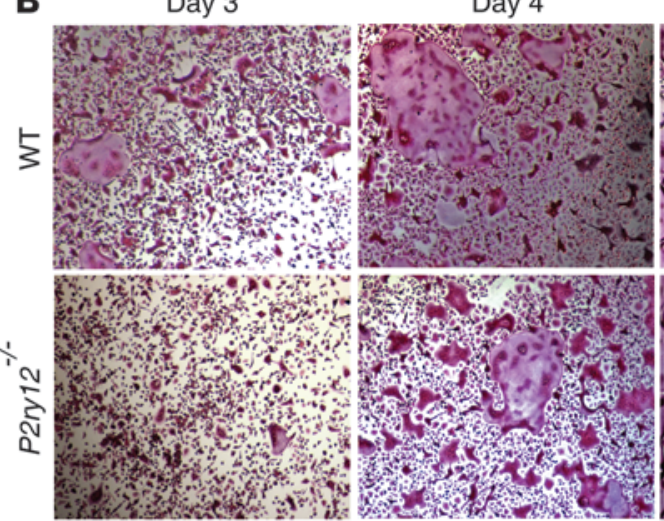

Day 5

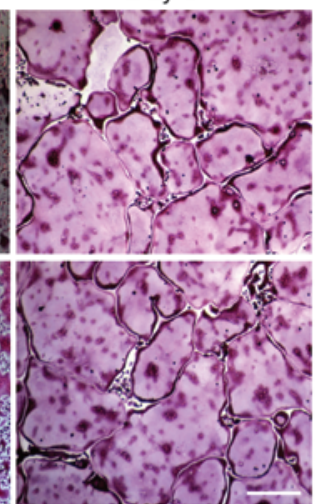

Ctsk

E

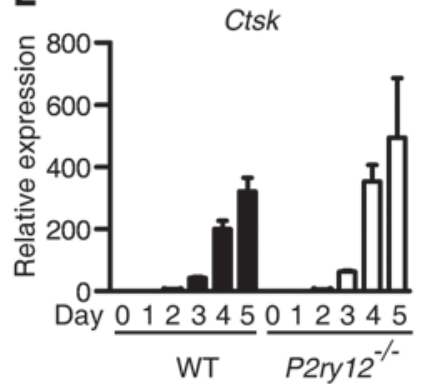

C

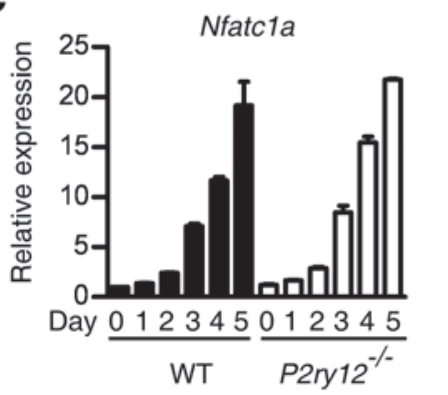

D

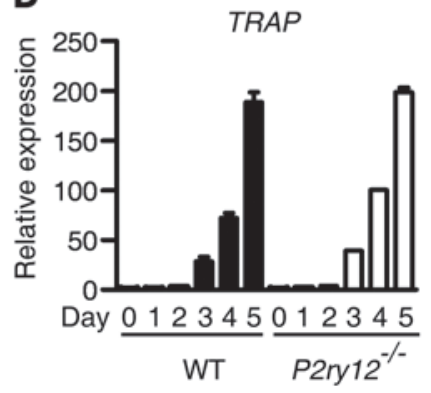

H Media

G

$\mathbf{F}$
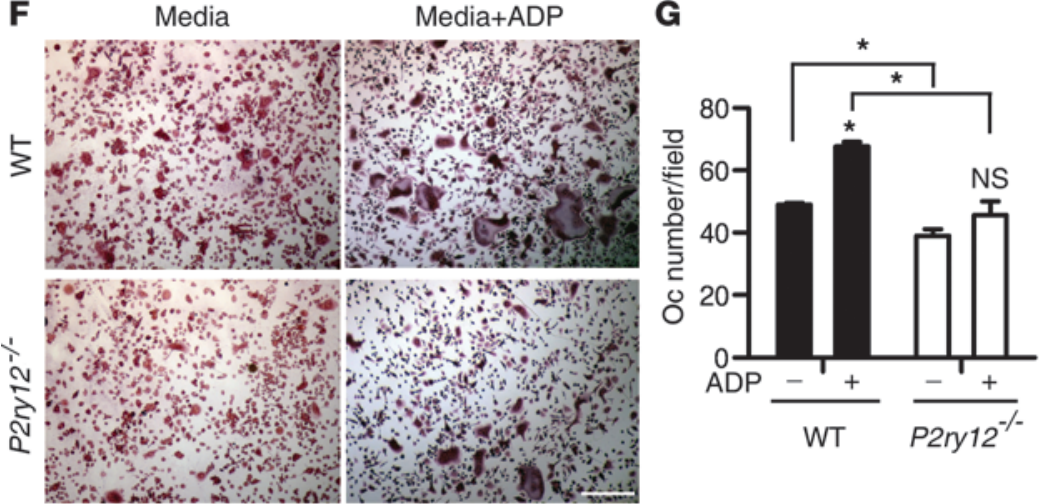

H
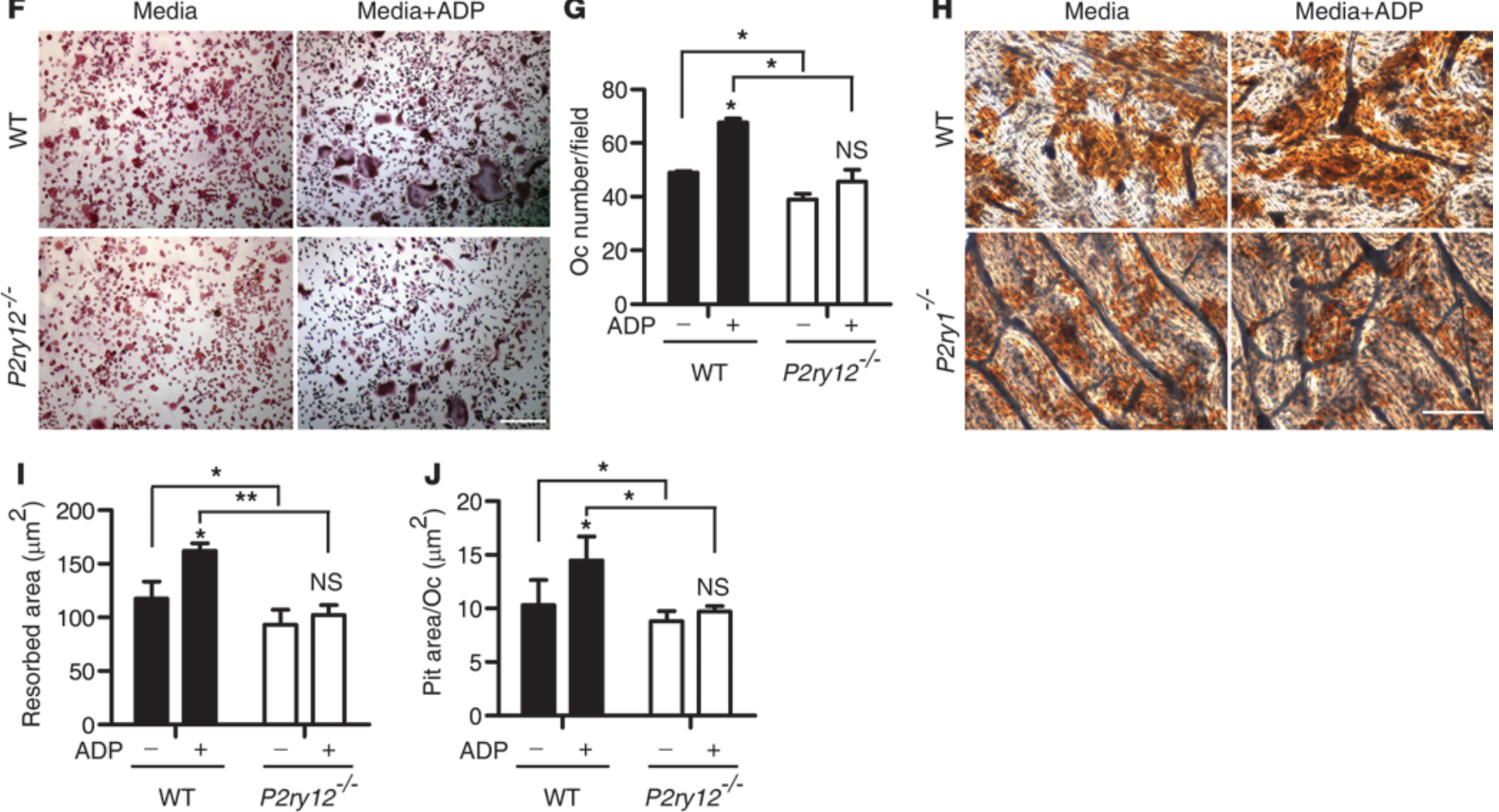

Figure 2

ADP enhances ex vivo OC bone resorption primarily through the P2RY12 receptor. (A) Quantitative real-time PCR of $P 2 r y 12$ expression on day 0 through day 5 of OC differentiation. (B) WT and P2ry $12^{-1-}$ OCs stained for the OC marker protein TRAP on days 3-5 of OC differentiation. Scale bar: $300 \mu \mathrm{m}$. (C-E) Quantitative real-time RT-PCR of OC differentiation markers; nuclear factor of activated T cells, cytoplasmic $1 \alpha$ (Nfatc1 $\alpha$ ), TRAP, and cathepsin K (Ctsk), normalized to levels of gapdh, comparing WT (black bars) and $P 2 r y 12^{--}$(white bars) cells on days $0-5$ of OC culture. (F) WT and $P 2 r y 12^{--}$macrophages were cultured with $50 \mathrm{ng} / \mathrm{ml} \mathrm{M-CSF}$ and $50 \mathrm{ng} / \mathrm{ml}$ RANKL and treated with or without $1 \mu \mathrm{M}$ ADP for 3 days. Day 3 OC culture was stained for the OC marker protein TRAP. Scale bar: $300 \mu \mathrm{m}$. (G) Quantitation of OC number ( $\geq 3$ nuclei). (H) BMMs derived from 8-month-old WT or $P 2 r y 12^{-/-}$mice were cultured with RANKL and MCSF on bone slices for 5 days. ADP was added at a final concentration of $1 \mu \mathrm{M}$ where indicated. Scale bar: $100 \mu \mathrm{m}$. (I and J) Quantification of bone pit area. Data represent mean \pm SD. $n=3$ per condition. ${ }^{*} P<0.05 ;{ }^{* \star} P<0.01$. 

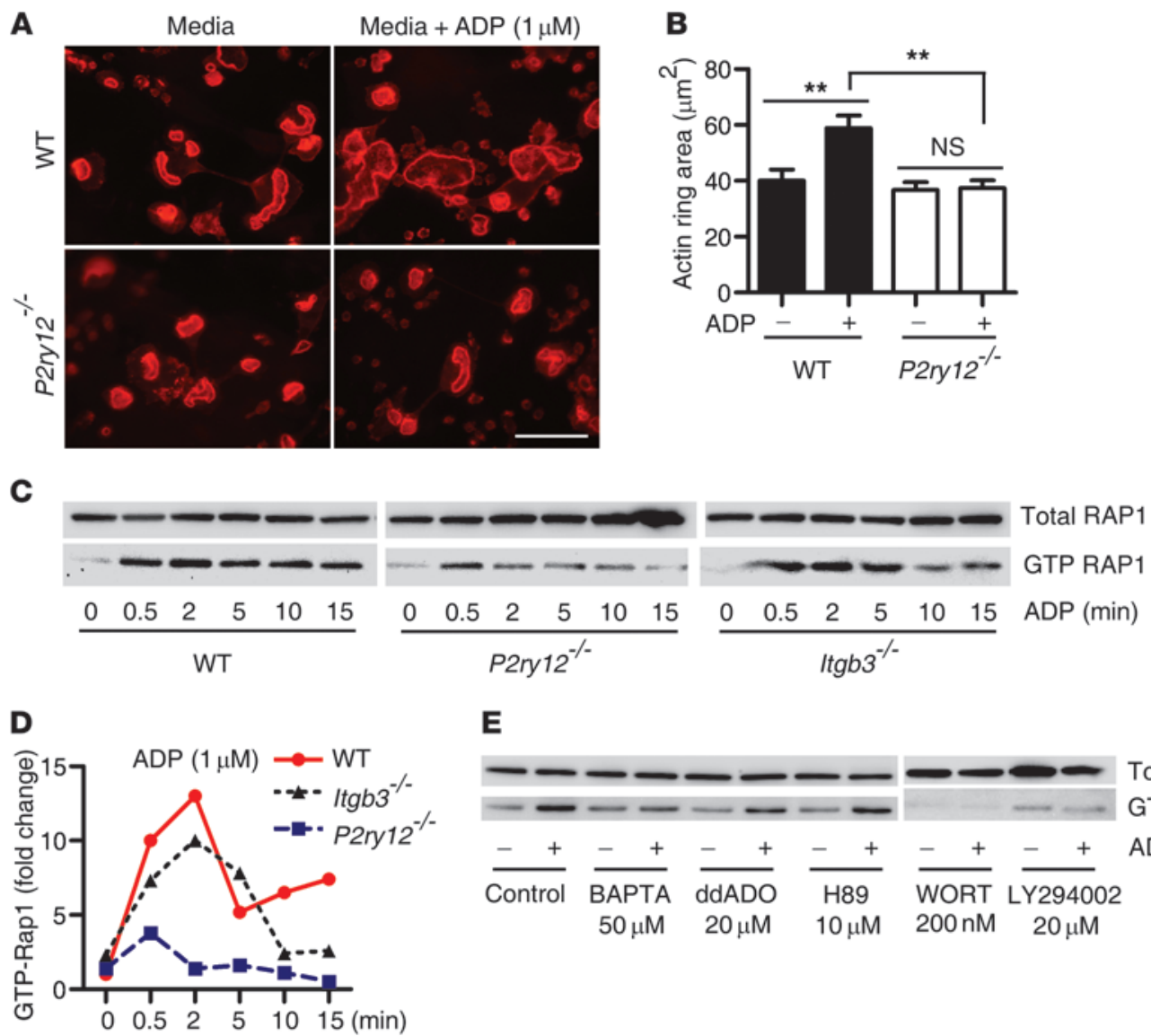

$\mathbf{E}$

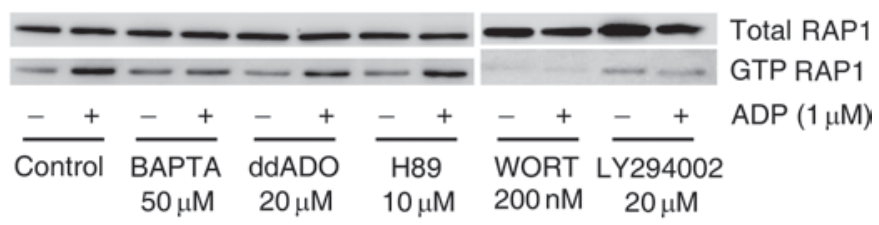

Figure 3

P2ry12-- OCs showed impaired ADP-induced RAP1 activation. (A and B) BMMs derived from 8-month-old WT or P2ry12-/- mice were cultured with RANKL and MCSF on bone slices for 5 days. ADP was added at a final concentration of $1 \mu \mathrm{M}$ where indicated. (A) Actin ring formation was determined by immunofluorescence following Rhodamine-phalloidin staining. Scale bar: $100 \mu \mathrm{m}$. Actin ring area was quantitated in B. (C) Western blots of total RAP1 and RAP1-GTP in ADP-stimulated pre-OCs (day 3 OC culture). WT and P2ry $12^{-/-}$pre-OCs were treated with ADP (1 $\mu$ M) for 0-15 minutes. Total RAP1 was detected in total cell lysate, while activated RAP1 (RAP1-GTP) was pulled down by using Ral GDS-RBD-labeled agarose beads. (D) Densitometry of GTP-RAP1 induction versus WT time 0 . (E) WT pre-OCs were treated with or without $1 \mu M$ ADP and BAPTA, ddADO, H89, or inhibitors of PI3K (wortmannin or LY294002), as indicated. Total RAP1 and activated RAP1 were detected as above. Data represent mean \pm SD and are representative of at least 3 experiments. ${ }^{* *} P<0.01$.

ankle swelling (Figure 4, A and B). However, CTX levels indicative of bone resorption were significantly decreased in $P 2 r y 12^{-/-}$mice compared with WT (Figure 4C). Histological analysis of ankle joints showed no differences in numbers of $\mathrm{TRAP}^{+} \mathrm{OC}$ per bone surface, but did show significantly decreased OC surface per bone surface (Figure 4, D-G) and a decrease in $\mathrm{TRAP}^{+}$area over total tissue area in $P 2 r y 12^{-/-}$mice. This result mirrors the in vitro findings (Figure $2, \mathrm{~F}-\mathrm{H}$ ) that the P2ry $12^{-/-}$OCs specifically showed decreased function without a significant change in number. Finally, WT mice with STA exhibited a significant decrease in BMD in the calcaneal bones as measured by $\mu \mathrm{CT}$ compared with $P 2 r y 12^{-1-}$ mice (Figure 4, $\mathrm{H}$ and I). These data demonstrate that P2ry $12^{-1-}$ mice were partially protected from arthritis-associated bone loss despite the development of joint inflammation.

Genetic and pharmacologic inhibition of P2RY12 protected mice from tumor-associated bone loss. OC recruitment and activation play a critical role in tumor-associated bone loss, pathologic fracture, and pain associated with bone metastases (2). Syngeneic osteolytic B16-F10 melanoma cells were inoculated directly into 1 tibia and PBS injected into the contralateral tibia of 8-week-old WT and $P 2 r y 12^{-/-}$mice. The tumor burden between WT and P2ry $12^{-/-}$mice was not significantly different as measured by bioluminescence imaging (BLI) (Figure 5, A and B); however, $\mu$ CT showed that WT mice displayed significant trabecular bone loss in the tumor-bearing tibiae, whereas $P 2 r y 12^{-/-}$mice maintained bone volume equivalent to that in the saline-injected tibiae (Figure 5, C and D). Histomorphometric evaluation revealed a significant increase in $\mathrm{OC}$ number and surface in tumor-bearing WT tibiae compared with saline-injected tibiae, whereas OC parameters were equivalent in both P2ry $12^{-/-}$bones (Figure 5, E and F), suggesting that P2RY12 was involved in tumor-induced recruitment of OC.

We next examined the effects of pharmacologic P2RY12 inhibition in a model of bone metastasis. Clopidogrel, a specific and irreversible P2RY12 antagonist, is commonly prescribed to inhibit platelet aggregation in coronary artery disease, peripheral vascular disease, and cerebrovascular disease $(11,54)$. Bone metastases were established using a tumor model of intracardiac injection of the syngeneic osteolytic 4T1-GFP-FL murine 
A

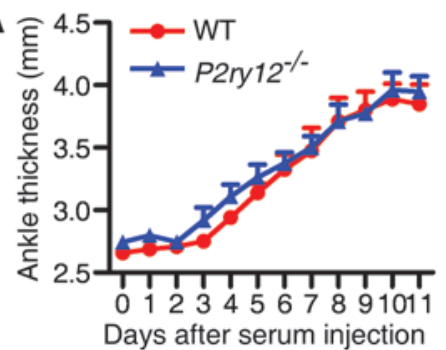

D
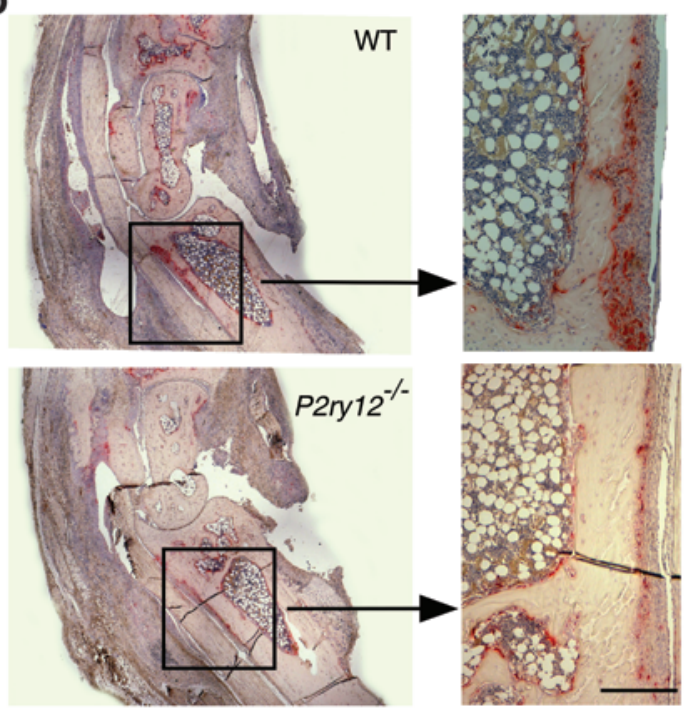

H

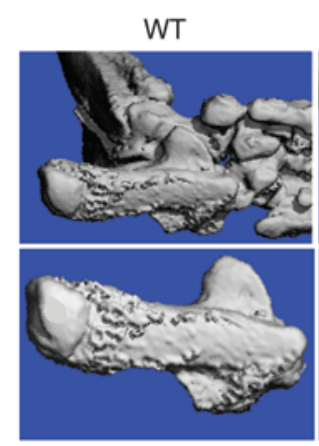

B

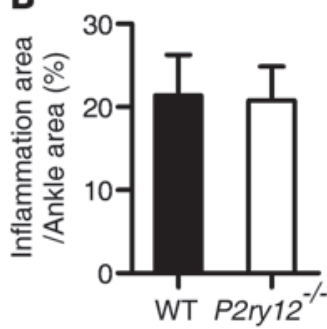

C

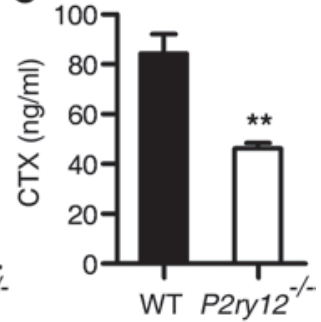

E

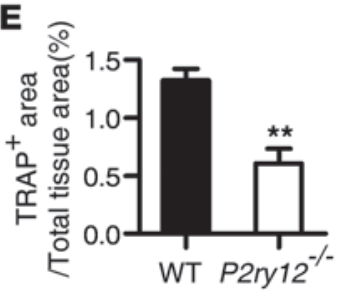

$\mathbf{F}$

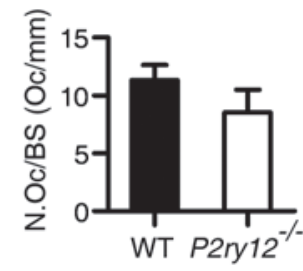

G

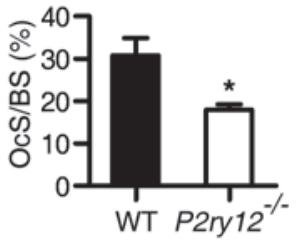

I

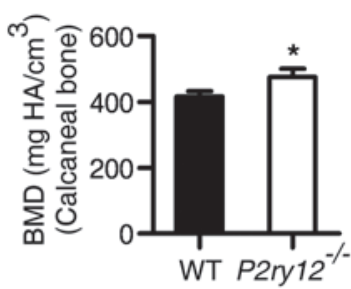

Figure 4

P2ry $12^{-/-}$mice had decreased arthritis-associated bone loss. STA was induced in 6-week-old WT $(n=8)$ or P2ry $12^{-/-}(n=6)$ mice by injection of $\mathrm{K} / \mathrm{BxN}$ serum on days 0 and 2. (A) Hind paw thickness was measured bilaterally daily. (B) Inflammation area over total ankle area was determined by measuring inflammatory tissue area on hematoxylin staining of ankle tissue. (C) Serum CTX assay to measure OC activity on day 11. $n=5$ per group. (D-F) Histological analyses of ankle with TRAP staining. Scale bar: $100 \mu \mathrm{m}$. Scale bar: $100 \mu \mathrm{m}$. Quantitation of $\mathrm{TRAP}^{+}$area (E), OC number (N.) per bone surface $(\mathbf{F})$, and OC surface per bone surface $(\mathbf{G})$ in the boxed ROI. (H and I) Representative $\mu \mathrm{CT}$ 3D reconstructions of hind limb ankle joints 11 days following STA induction and calcaneal bone BMD are shown. Scale bar: $300 \mu \mathrm{m}$. Data represent mean \pm SD. ${ }^{*} P<0.05 ;{ }^{* *} P<0.01$. mammary carcinoma cell line into immunocompetent BALB/c mice. Beginning 2 days after tumor inoculation, clopidogrel $(30 \mathrm{mg} / \mathrm{kg})$ or vehicle was administered in the drinking water for 9 days. We did not observe any change in body weight, fur ruffling, general activity, and appearance of mice that were treated with clopidogrel. As expected, mice that received clopidogrel had an increased bleeding time. Clopidogrel administration did not affect tumor burden (Figure 6, A and B), but increased tibial BV/TV and BMD compared with vehicle-treated tumor-bearing mice (Figure 6, C and D). While there was no significant decrease in OC number, clopidogrel treatment significantly reduced the OC surface per trabecular bone surface (Figure 6, E-G). Interestingly, clopidogrel treatment was associated with increased tibial BV/TV and BMD and decreased CTX in non-tumor-bearing 6-week-old WT mice (Supplemental Fig- ure 7, A-D). Together, these results demonstrate that $P 2 r y 12^{-/-}$ mice and clopidogrel-treated WT mice were protected from tumor-induced osteolysis through effects on OCs.

P2RY12 antagonism partially protected mice from ovariectomy-induced bone loss. Because P2ry $12^{-/-}$mice were partially protected from ageassociated bone loss (Figure 1), we evaluated whether the absence of P2RY12 could prevent bone loss in a model of estrogen deficiency-induced osteoporosis. Ovariectomy (OVX) was performed on P2ry $12^{--}$and WT littermates at 14 weeks, an age at which no significant differences in baseline BV/TV were observed. At 2 and 5 weeks after OVX, P2ry $12^{-/-}$mice had lost significantly less tibial bone mass than WT controls (Figure 7A). Serum CTX was significantly lower in P2ry $12^{-/-}$mice after OVX, whereas serum P1NP (Figure 7B) and BFR (Figure 7, C and D) were not significantly changed. In agreement, histomorphometric analysis showed that the number 
A

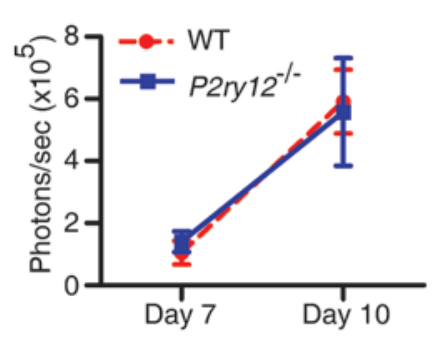

B

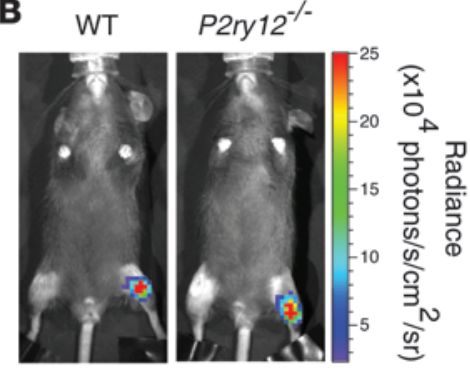

C

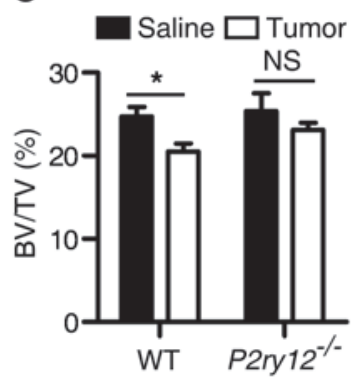

D

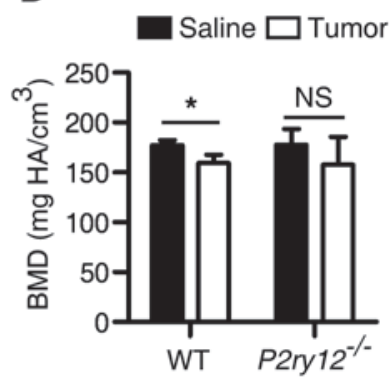

E

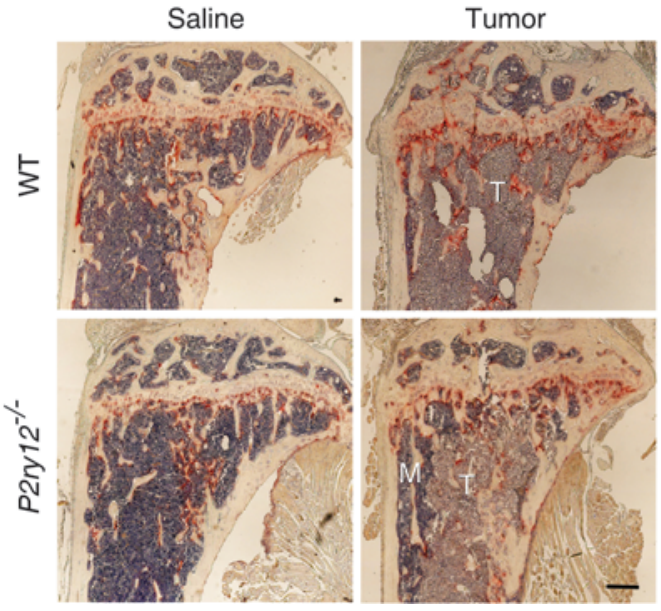

$\mathbf{F}$

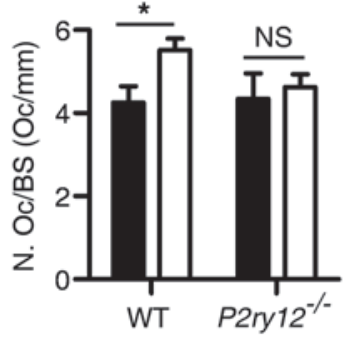

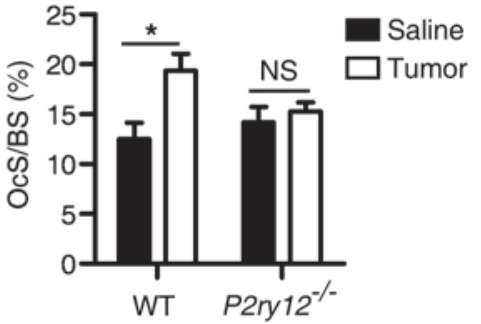

Figure 5

Genetic inhibition of P2RY12 protected mice from tumor-associated bone loss. (A and B) $1 \times 10^{4}$ B16-FL tumor cells (right leg) or PBS (control, left leg) were injected directly into the tibia ( $n=6$ per group). (A and B) The tumor burden in hind limbs was measured by BLI. (C and $\mathbf{D})$ BV/TV and BMD in the primary and secondary spongiosa of PBS-injected or tumor-bearing tibia were analyzed by $\mu C T$. (E) TRAP-stained tibial sections ( $\times 4$ ) of WT (top) and P2ry $12^{-/-}$mice (bottom) 10 days after tumor injection. T, tumor; M, marrow. TRAP+ staining (dark red areas) indicates OC presence. Scale bar: $300 \mu \mathrm{m}$. (F) OC number and surface per bone surface in the primary and secondary spongiosa of the tibia are shown in saline-injected tibia (S) (black bars) and tumor-injected tibia (T) (white bars). Data represent mean \pm SD. $n=6 .{ }^{*} P<0.05$.

and surface area of OCs were significantly higher in the femoral bones of WT mice compared with P2ry12 $12^{-/}$mice, whereas OB number and surface area were not significantly different between WT and P2ry $12^{-/-}$mice following OVX (Figure 7, E and F). BMD did decline in $P 2 r y 12^{-/-}$mice after OVX by day 35, but to a lesser extent than in WT mice. Together, these data suggest that P2ry $12^{-/-}$mice were partially protected from OVX-induced bone loss.

Likewise, pharmacologic inhibition of P2RY12 with clopidrogel (orally administered at $30 \mathrm{mg} / \mathrm{kg} / \mathrm{d}$ ) protected WT mice from significant OVX-induced bone loss at day 14 compared with sham surgery control (Figure 8A). At day 35, all OVX mice experienced significant bone loss compared with sham controls; however, clopidogrel-treated mice remained partially protected from OVX-mediated bone loss compared with vehicle controls (Figure 8B). At day 14, serum CTX and P1NP levels were elevated in both OVX groups compared with sham groups, indicative of increased bone turnover (Figure 8C); however, clopidogrel treatment significantly decreased CTX levels compared with vehicle, demonstrating that P2RY12 antagonism blunted osteoclastic bone resorption. While the overall extent of bone turnover was decreased by day 35 after OVX, serum CTX levels remained significantly higher in vehicle-treated mice that had undergone OVX compared with sham-treated mice, while clopidogrel treatment decreased the CTX levels of OVX mice to a point equivalent to that of the sham control group (Figure 8C). Serum P1NP levels showed no significant difference between groups at day 35 (Figure 8C). Clopidogrel treatment blunted the increase in OC number and OC surface per bone surface observed in vehicle-treated mice following OVX at day 14 and day 35 (Supplemental Figure 8, A and B, and Figure 8, D and E). OB number and surface per bone surface were not significantly different between clopidogrel and vehicle treatment (Supplemental Figure 8, A and B). Likewise, although OVX itself did cause a decrease in BFR at day 14, but not day 35, P2RY12 antagonism with clopidogrel did not alter this response compared with vehicle (Supplemental Figure 8, $\mathrm{C}-\mathrm{F})$. In agreement with results obtained with genetic disruption of P2ry12, these data demonstrate that pharmacologic blockade of P2RY12 partially protected mice from OVX-induced bone loss and that the protection was predominantly from a blunting of OC-mediated resorption.

\section{Discussion}

In this report, we demonstrate what we believe is a novel role for the ADP receptor P2RY12 in the function of bone-resorbing OCs, particularly in preclinical models of pathologic bone loss associated with postmenopausal osteoporosis, rheumatoid arthritis, 
A

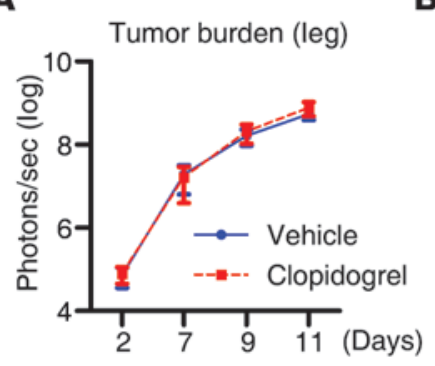

B

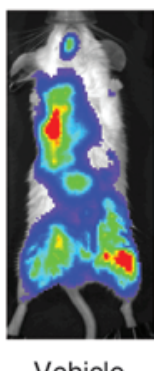

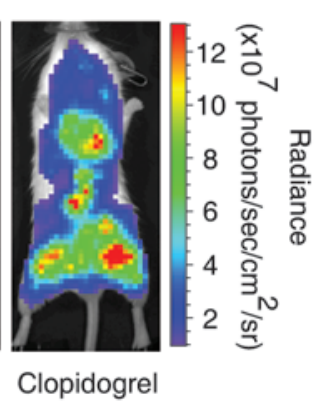

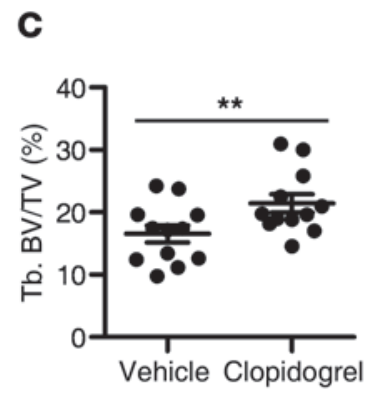

D

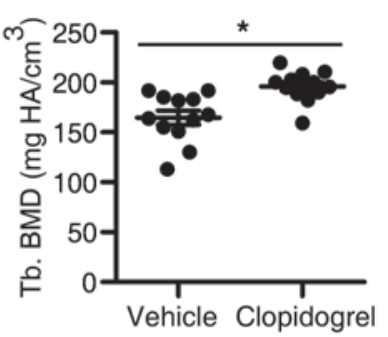

E

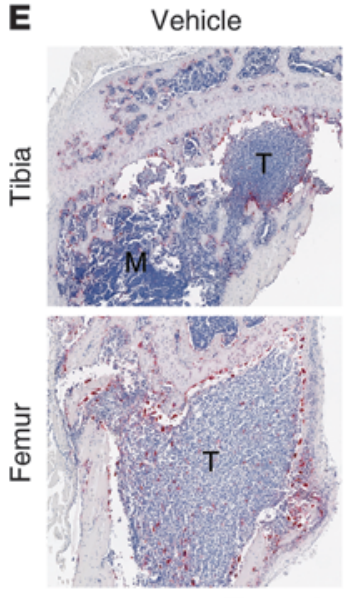

Clopidogrel

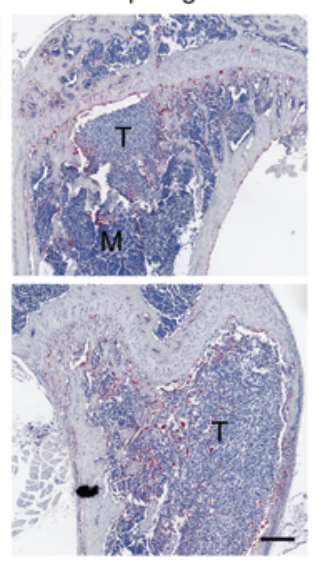

$\mathbf{F}$

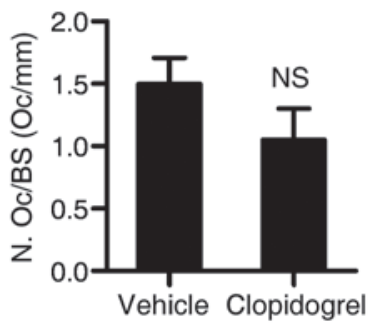

G

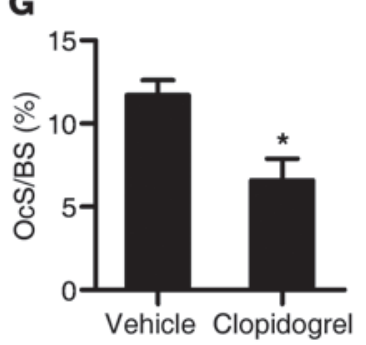

Tumor-bearing mice

\section{Figure 6}

Pharmacologic inhibition of P2RY12 protected mice from tumor-associated bone loss. 4T1-GFP-FL tumor cells were directly injected into the left cardiac ventricle of WT Balb/c mice ( $n=12$ per group). Clopidogrel treatment $(30 \mathrm{mg} / \mathrm{kg} / \mathrm{d}$ in drinking water) was begun 2 days after tumor cell injection and continued for 9 days. (A) The tumor burden in hind limbs measured by BLI and (B) representative pictures of BLI at day 11. (C and D) $B V / T V$ and BMD of the tibia of tumor-bearing mice at day 11 were analyzed by $\mu \mathrm{CT}$. (E) TRAP-stained hind limb sections at day 11 after tumor injection and vehicle or clopidogrel treatment. TRAP+ staining (dark red areas) indicates OC presence. Scale bar: $300 \mu \mathrm{m}$. OC number and surface in the primary and secondary spongiosa of the tibia are shown $(\mathbf{F}$ and $\mathbf{G})$. Data represent mean $\pm \mathrm{SD}$. ${ }^{\star} P<0.05$; ${ }^{\star *} P<0.01$.

and bone metastases. We demonstrate that antagonism with the FDA-approved P2RY12 inhibitor, clopidogrel, decreased bone loss in murine models of osteoporosis and tumor-associated bone loss. These data suggest that clopidogrel or novel ADP and P2RY12targeted therapies could be clinically evaluated in disease states characterized by excessive bone resorption.

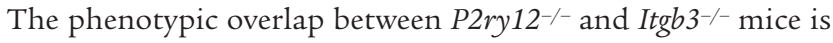
striking. $\operatorname{Igb} 3^{-/-}$mice have a severe platelet aggregation defect and have increased bone mass with decreased OC function $(25,47,55)$. P2ry $12^{-/-}$mice display similar defects in platelet aggregation (10) and osteoclastic bone resorption, albeit both are milder than those

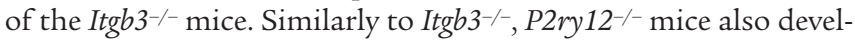
oped increased trabecular bone mass with aging due to impaired OC function and demonstrated protection from tumor-induced bone loss, again less severe than in the $\operatorname{Itg} b 3^{-1-}$ mice $(22,47)$. These results suggest that P2RY12 and $\beta_{3}$ integrin may lie in the same signaling pathway necessary for OC formation and function, as they do for platelet adhesion.

Decreased adhesion, actin ring formation, migration, and resorption of $\mathrm{Itgb3}^{-/-}$OCs have been reported (23). Adhesion is critical to the formation of actin rings in OCs and the sealing zone necessary for directional delivery of bone-resorbing enzymes and acids $(1,47,56)$. Because P2RY12 has previously been shown to play a role in adhesion in platelets and microglial cells $(10,29)$ and is required for microglial migration toward $\operatorname{ADP}(26,31,57)$, we evaluated its role in actin ring responses. Accordingly, we report a decrease in ADP-enhanced actin ring formation on bone by P2ry12-/- cells. We hypothesized that P2RY12 acts upstream of $\beta_{3}$ integrin through a GTPase-related mechanism in OCs similar to that in platelets and that RAP1 GTPase plays an important role in this signaling pathway. In addition to its typical $G \alpha_{i}$-coupled roles, P2RY12 is known to couple to the G $\beta \gamma$ portion of the G protein heterotrimer that activates PI3K, Akt, and eventually RAP1, leading to integrin activation in platelets $(12-15,17,58-62)$. We found that RAP1 activation was downstream of P2RY12 in pre-OCs and that this activation was ADP dependent.

Interestingly, $\beta_{3}$ integrin-null OCs had intact ADP-induced RAP1 activation, suggesting that $\beta_{3}$ integrins are downstream of P2RY12 signaling. P2Y1, another $\mathrm{Ga}_{\mathrm{q}}$-coupled ADP receptor, is also expressed by OC lineage cells; however, our data that responses to $\mathrm{ADP}$ were impaired in $\mathrm{P} 2 \mathrm{ry} 12^{-/-}$but not $\mathrm{P} 2 \mathrm{ry} 1^{-/-}$cells suggest that P2RY12 is necessary for the majority of ADP-dependent RAP1 activity in OC. We cannot rule out that P2Y1 may cooperate with P2RY12 during osteoclastogenesis in situations associated with increased 
A

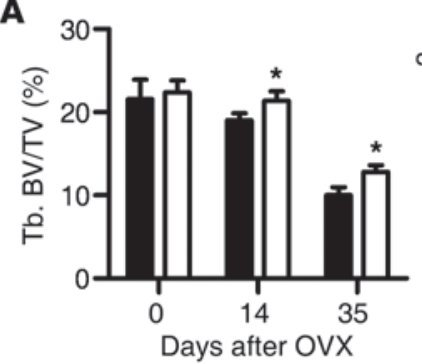

C

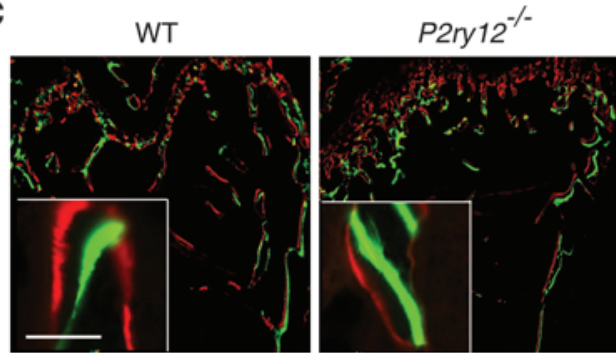

Day 14 (post OVX)

E

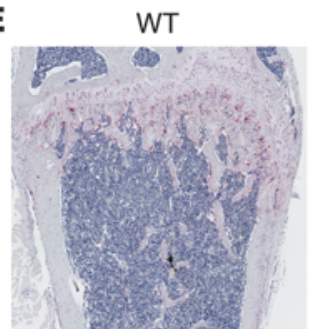

Day 14 (post OVX)

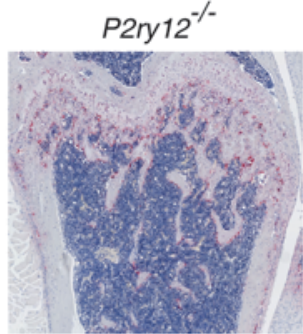

B

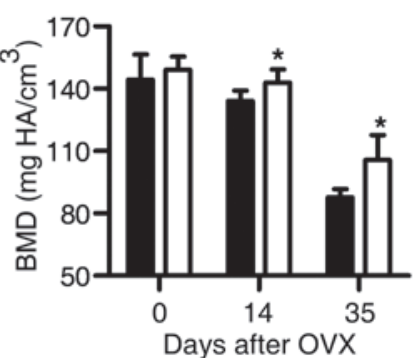

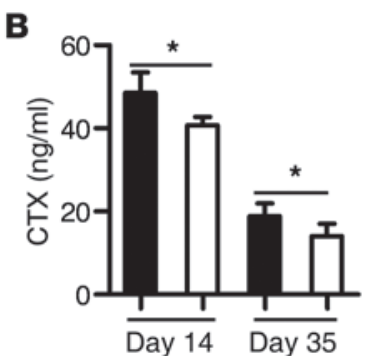

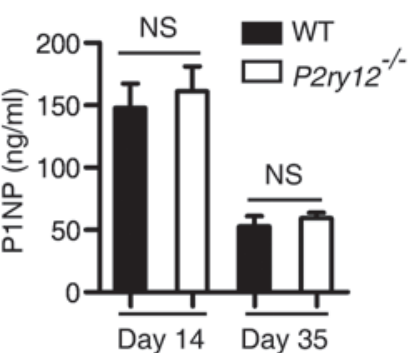

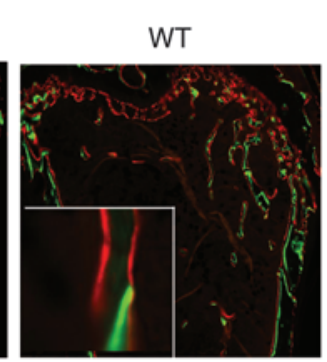

Day 35 (post OVX)
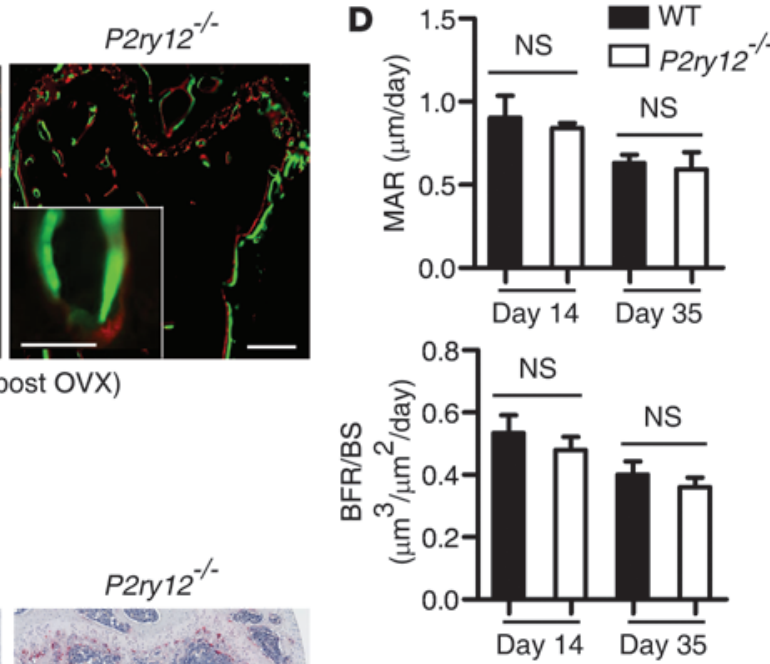

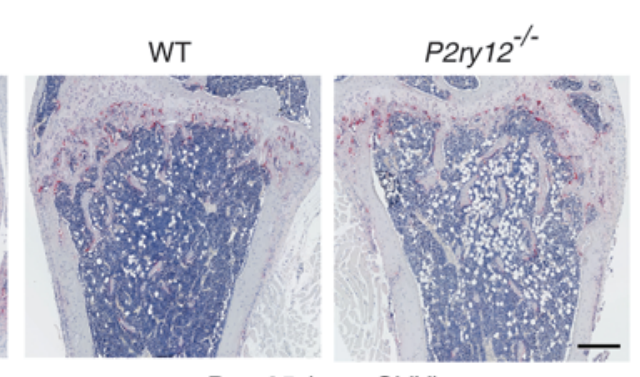

Day 35 (post OVX)
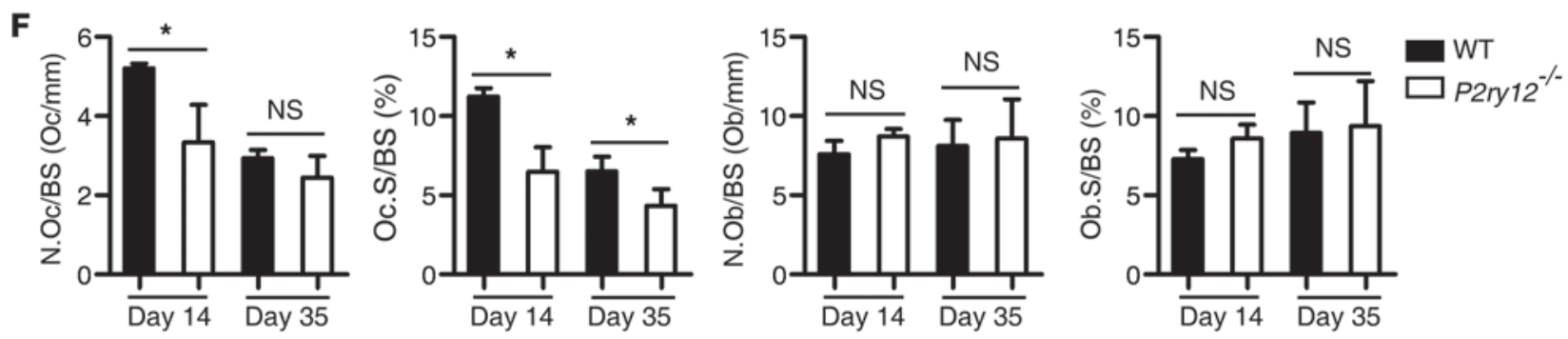

Figure 7

$P 2 r y 12^{-/-}$mice were partially protected from OVX-induced bone loss. OVX was performed on 14-week-old $P 2 r y 12^{-/-}$and WT littermates $(n=5$ per group). (A) BV/TV and BMD were measured in the primary and secondary spongiosa of the tibia of live animals viva CT scanning prior to and at days 14 and 35 following OVX. (B) Serum concentration of CTX and P1NP measured by ELISA. (C) Bone formation was visualized by calcein (first) and alizarin red (second) double-labeling and visualized in the trabecular bone. Representative photographs: original magnification, $\times 2.5$, scale bar: $300 \mu \mathrm{m}$; original magnification, $\times 20$, scale bar: $50 \mu \mathrm{m}$. (D) MAR and BFR were measured. (E) TRAP-stained hind limb sections after OVX. Scale bar: $300 \mu \mathrm{m}$. (F) Quantification of OC and OB cells in the primary and secondary spongiosa of the femur. Data represent mean \pm SD. $n=5 .{ }^{*} P<0.05$.

extracellular ATP/ADP. Likewise, RAP1 activation can also modulate outside-in integrin signaling, which is critical to OC function $(12,24,63)$. Taken together, our data suggest that ADP-mediated RAP1 activation occurs in OC and is largely dependent on P2RY12.
In addition to RAP1, P2RY12 may also be upstream of other GTPases, such as Rac or Cdc42, which are also critical to OC function $(63,64)$. The potentially varying role of different purinergic receptors and RAP1 in OCs is currently under investigation. We 

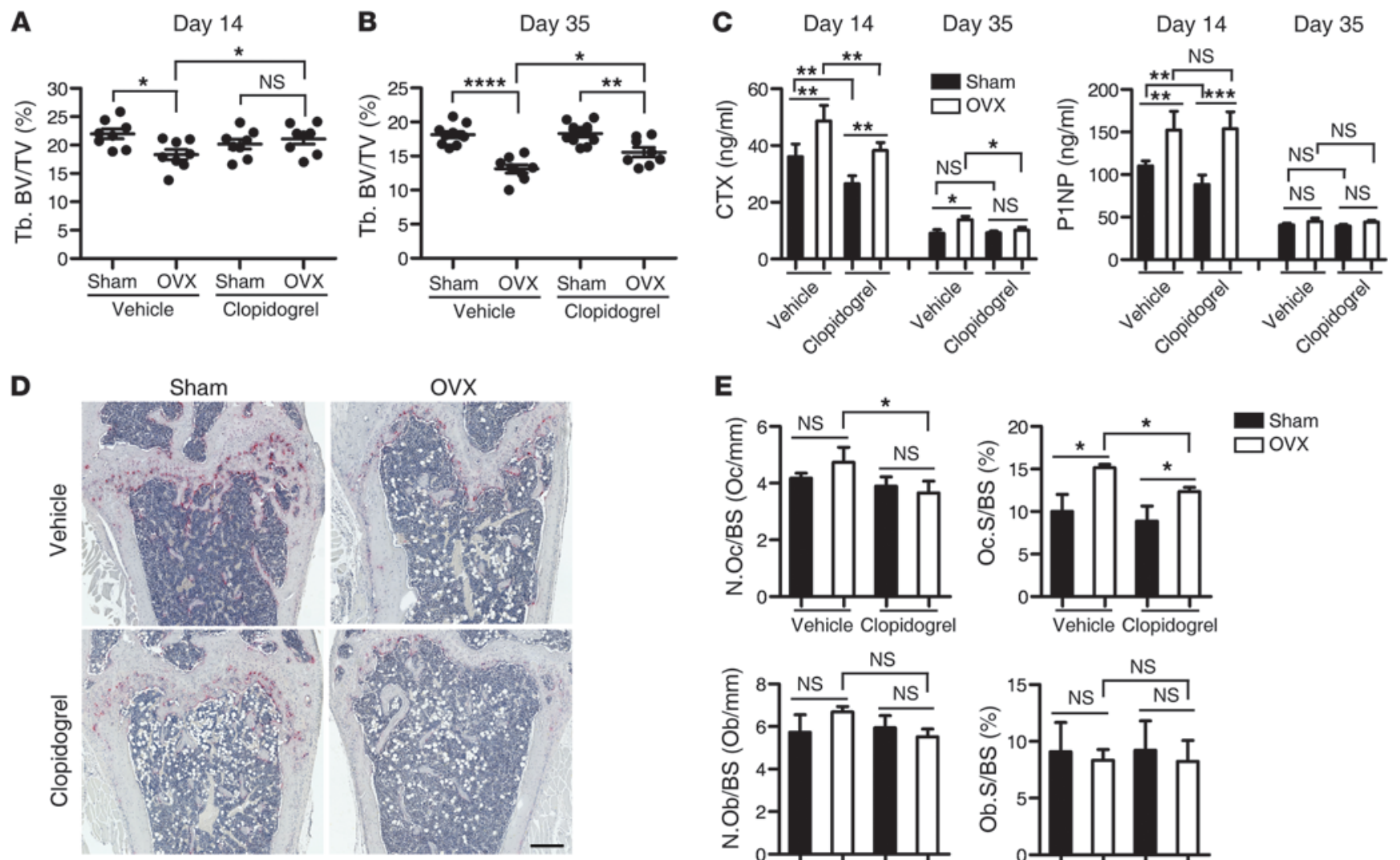

(Day 35)
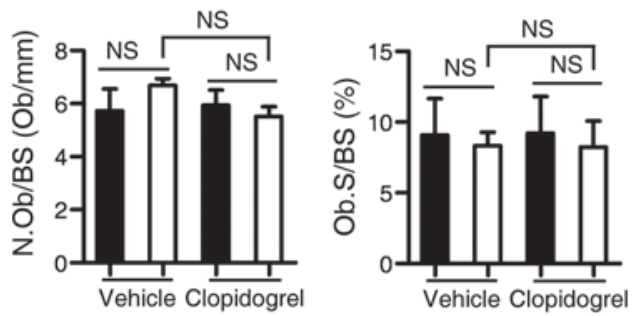

Figure 8

P2RY12 antagonism partially protected mice from OVX-induced bone loss. 14-week-old WT C57BL/6 mice underwent OVX $(n=8)$ or sham operation (sham) $(n=10)$ and were treated with clopidogrel (30 mg/kg/day) or vehicle-control in drinking water for 2 or 5 weeks. Tibias from sham-operated and OVX mice were examined by $\mu$ CT. (A and B) BV/TV in the primary and secondary spongiosa of the tibia after OVX. (C) Serum concentration of CTX and P1NP measured by ELISA. (D) TRAP-stained hind limb sections after OVX. Scale bar: $300 \mu \mathrm{m}$. (E) Quantification of OC and OB cells 35 days after OVX. OC number (N.OC) per bone surface (N.OC/BS) and OB number per bone surface (N.OB/BS) in the primary and secondary spongiosa of the femur. Data represent mean \pm SD. $n=5$. ${ }^{*} P<0.05 ;{ }^{* *} P<0.01$; ${ }^{* * *} P<0.001 ;{ }^{* * *} P<0.0001$.

cannot conclude that the activation of P2RY12 yields activation of only $\beta_{3}$-containing integrins, since RAP1 activity is upstream of many integrin heterodimers $(12,14,20,49)$. We propose that activation of specific integrins by P2RY12 and other purinergic receptors may exist at different phases of OC formation, such as fusion and migration; this hypothesis will be tested in future studies.

Our studies demonstrated that P2RY12 exerts its most prominent effects on bone during pathological situations in which extracellular ATP would be increased due to ongoing tissue damage and repair. Extracellular ATP can be degraded into ADP by extracellular dephosphorylating enzymes; therefore, the extracellular ADP concentration is positively corelated with extracellular ATP levels. Tumor cells are known to establish a microenvironment containing more than $100 \mu \mathrm{M}$ extracellular ATP, whereas ATP concentration is undetectable in healthy tissues (36). Likewise, the ATP concentration in synovial fluid from patients with rheumatoid arthritis is substantially elevated at $50 \mathrm{nM}$, but undetectable in normal joint fluids (43). Thus, under normal physiologic conditions, there is a minimal concentration of extracellular ATP in tissues and blood. Thus, the minimal effects on in vivo bone mass observed in healthy 2-month-old
P2ry $12^{-/-}$mice may be attributed to low extracellular ADP/ATP concentrations present under these conditions. In contrast, the increased amounts of bone remodeling and tissue repair associated with aging skeletons and organs likely release ATP, resulting in increased P2RY12 signaling, similar to that occurring in the presence of tumor or inflammatory stimuli. Under such conditions of aging (8-month-old mice) or pathology, we found that the genetic absence or pharmacological inhibition of P2RY12 blunted OC function, resulting in a preservation of bone mass. Interestingly, the administration of clopidogrel to non-tumorbearing 6-week-old mice, a time at which bone turnover (and thus, likely extracellular ATP/ADP) is high due to skeletal growth, also increased bone volume. However, drug administration to 16 -weekold mice (sham surgery group in Figure 8), a time when peak bone mass has already been mostly reached and thus turnover and ATP release would be expected to be decreased, did not affect bone mass. In experiments using both genetic and pharmacologic disruption of $P 2 R Y 12$, we observed the most protection from bone loss after OVX occurred within the first 2 weeks. We hypothesize that extracellular ADP levels are likely higher in the early time points after OVX, but it is also possible that P2RY12 disruption 
could cause small sequential decreases in OB formation in the later time points. Therefore, the clinical benefit of P2RY12 inhibition or antagonism may be strongest during the early/peak time period after injury or pathology.

The dosage of clopidogrel used in the in vivo studies was 30 $\mathrm{mg} / \mathrm{kg} / \mathrm{d}$, which, after species conversion, is higher than the standard $75 \mathrm{mg} / \mathrm{d}$ dosage used in humans. However, except for the expected longer bleeding time, we did not observe any negative effects on general health, such as weight, grooming behavior, and activity level. There could be indirect effects on bone of high-dose clopidogrel from effects on platelets and perhaps off-target effects. Thus, it is possible that some of the bone effects from clopidogrel may not be present or may be different at lower doses, and this will be explored in future studies.

In the disease models examined here, the effects of P2RY12 on osteolysis and bone resorption predominated, and P2RY12 genetic deletion or pharmacological inhibition consistently yielded a net increase in bone mass. However, we cannot rule out that P2RY12 may have subtle effects on bone formation and OB function. In aging mice, we did not detect differences in OB number per bone surface in $P 2 r y 12^{-/}$and WT mice, but there probably was an absolute increase in $\mathrm{OB}$ number, given the higher BV/TV in P2ry $12^{-/-}$ mice. Thus, the function of individual OBs could be decreased, but this could have been balanced by the increased number to give a constant P1NP. Notably, we did observe modest decreases in serum markers of both bone formation and resorption in 2-month-old P2ry $12^{-/-}$mice, although there were no changes in BMD or BFR in these young mice. This could be consistent with balanced and coupled bone formation and resorption that would have no net effect on bone volume. It is also possible that P2RY12 exerts a transient effect on OB function that may be reflected by serum $\mathrm{P} 1 \mathrm{NP}$ at a single, discrete time point, but did not result in a measurable change in the cumulative BFR measured over a period of 5 days. Such transient versus cumulative measurements of OB activity may also account for the observation of increased P1NP, yet decreased BFR, observed 2 weeks following OVX (Figure 8 and Supplemental Figure 8). A detailed analysis of the vertebral and femoral bones throughout the life span of $P 2 r y 12^{-/-}$mice will be important. Taken together, it is possible that P2RY12 may decrease OB function, but in the in vivo models that we evaluated, the OC dysfunction predominated, resulting in an overall increase in BV/TV. The role of P2RY12 in OBs is under intense study.

It has been reported that purinergic signaling can modulate platelet function, inflammation, and pathologic angiogenesis, which could modulate bone cell function in certain disease states $(2,22,36,65-68)$. Recent preclinical data is conflicting regarding the role of clopidogrel in inflammation both dependently and independently of its effects on platelets $(36,68)$. We found that in the STA model, the amount of clinical inflammation as measured by paw swelling was similar between WT and $P 2 r y 12^{-/-}$mice. However, we cannot rule out that differences in specific inflammatory cytokines did not exist between genotypes, causing effects on pathologic osteolysis. Interestingly, $\beta_{3}$ integrins play a critical role in platelet function, OC function, inflammatory responses, and pathologic angiogenesis $(69,70)$. It is possible that some of the bone resorption effects in the disease models evaluated in our P2RY12 studies could in part be due to non-cell-autonomous effects of P2RY12 signaling on neoangiogenesis, platelet activation, and/or inflammation. It has been reported that platelet defects in a mouse model of von Willebrand disease had increased bone mass (71). We have previously reported that mice with conditionally deleted $\beta_{3}$ integrin in platelets had normal bone mass despite severe platelet aggregation defects; conversely, mice with conditional deletion of $\beta_{3}$ integrin in myeloid/OC lineage cells had osteosclerosis and increased bone mass despite normal platelet function (72), suggesting that defective platelet function does not necessarily modulate bone mass.

Currently, there are no prospective clinical data on BMD in patients using clopidogrel. Interestingly, a population-based epidemiological study reported that the use of platelet inhibitors aspirin and dipyridamole was associated with increased risk of osteoporotic fractures, but this association was not observed with clopidogrel (73). Clinical studies evaluating the effects on bone in patients receiving clopidogrel or trials of clopidogrel in patients with excessive bone resorption are warranted to determine whether clopidogrel or other novel ADP and P2RY12-targeted therapies $(11,67,74)$ could have a role as in the treatment of disease states characterized by excessive bone resorption. We propose that P2RY12 targeting would likely only have effects on bone during localized increases in extracellular ADP that can occur during tissue damage, inflammation, and cancer, with little effects on normal systemic bone turnover. Our data suggest that antagonism of the ADP receptor, P2RY12, using currently available drugs could represent a new approach to preventing pathologic bone loss.

\section{Methods}

Mice. WT, P2ry $12^{-/-}$(10), and Itgb3 $3^{-/-}$mice (75) on a pure C57BL/6 background were housed under pathogen-free conditions according to the guidelines of the Division of Comparative Medicine, Washington University School of Medicine. Unless noted, all mice were used at 6 to 10 weeks of age. P2ry $1^{-/-}$BM cells (BMCs) were provided by Christian Gachet (Université de Strasbourg, Strasbourg, France) (76).

Micro-computed tomography. Tibial metaphyses were scanned by microcomputed tomography $(\mu \mathrm{CT})(\mu \mathrm{CT}-40$; Scanco Medical). The trabecular region from forty $2 \mathrm{D}$ slices $(0.8 \mathrm{~mm})$ in the primary and secondary spongiosa of the tibia was selected using contours inside the cortical shell on each $2 \mathrm{D}$ image, with the growth plate as a marker to determine a consistent location to start analysis. A 3D cubical voxel model of bone was built, and calculations were made for BV/TV and apparent BMD (calibrated against a hydroxyapatite phantom). A threshold of 300 (out of 1,000) was used to differentiate trabecular bone from nonbone.

Serum CTX and P1NP assays. CTX and P1NP were measured in fasting serum using ELISA systems (Immunodiagnostic Systems Inc.).

OC culture assay. To generate primary BMMs, whole BM was extracted from the femurs and tibias of mice and plated in petri dishes in $\alpha$-MEM medium containing $10 \%$ fetal bovine serum and M-CSF-containing CMG14-12 cell culture supernatant $(50 \mathrm{ng} / \mathrm{ml})$. For OC differentiation assays, BMMs were plated at $2 \times 10^{4}$ per well in 48 -well cell culture plates and fed daily with osteoclastogeneic medium ( $\alpha$-MEM containing $10 \%$ FBS, CMG14-12 supernatant [ $50 \mathrm{ng} / \mathrm{ml}]$, and GST-RANKL [ $50 \mathrm{ng} / \mathrm{ml}]$ ) for 3 to 6 days, as previously described (77). Then, $1 \mu \mathrm{M}$ ADP (Sigma-Aldrich) was added daily to cultures as indicated. TRAP staining was performed according to the manufacturer's instructions (Sigma-Aldrich). The number of TRAP ${ }^{+}$ OCs with 3 or more nuclei were counted using ImageJ software (NCBI).

In vitro bone resorption assay. Bone resorption assays were performed as previously described (77). For actin ring staining, cells were cultured on bovine bone slices in osteoclastogeneic medium with or without $1 \mu \mathrm{m}$ ADP for 6 days. Cells were fixed in $4 \%$ paraformaldehyde, permeabilized in $0.1 \%$ Triton X-100, rinsed in PBS, and immunostained with Alexa Fluor 488 phalloidin (Molecule Probes) or Rhodamine-phalloidin 
(Invitrogen). To quantify resorption lacunae, cells were removed from bone slices, and bone slices were incubated with peroxidase-conjugated wheat germ agglutinin (WGA) (Sigma-Aldrich) and stained with 3,3'-diaminobenzidine (Sigma-Aldrich). Resorption area was determined from five $4 \times$ fields using BioquantOsteo software (Bioquant) by an operator blinded to genotype.

RAP1 pull down assays and Western blotting. BMMs derived from 2-monthold mice and OCs were cultured as above; day 3 OCs (pre-OCs) were used for experiments. After ADP $(0-1 \mu \mathrm{m})$ or CMG-14-12 supernatant (100 $\mathrm{ng} / \mathrm{ml}$ ) treatment, cells were washed in PBS and harvested into Tris Lysis Buffer (TLB) (50 mM Tris-HCl, pH 7.4, 500 mM NaCl, 1\% NP40, 2.5 mM $\mathrm{MgCl}_{2}$, and $10 \%$ glycerol) plus $1 \%$ Mammalian Protease Inhibitor Cocktail (Sigma-Aldrich). As indicated, cells were also treated with PI3K inhibitor (wortmannin or LY294002), inhibitor for adenylate cyclase (ddADO), or PKA (H89), or by chelation of calcium (BAPTA). A sample of the supernatant was incubated with Ral GDS-RBD-labeled Agarose Beads (Upstate Biotechnology) for 45 minutes at $4^{\circ} \mathrm{C}$. After washing, bound RAP1-GTP was released from the beads by boiling in $2 \times$ Laemmli reducing sample buffer. Western blotting was used to detect total RAP1 and RAP1-GTP using rabbit anti-RAP1a/1b antibody (Cell Signaling Technology Inc.), secondary HRP-conjugated goat anti-rabbit IgG (Calbiochem), and chemiluminescent substrates for HRP (SuperSignal; Thermo Scientific). Densitometry, where appropriate, was performed using Quantity One software ver. 4.5.1 (Bio-Rad).

STA. The STA model was described previously (53). Briefly, 6-week-old WT and P2ry $12^{-/-}$mice were used in this model; arthritis was induced by injection of serum from arthritic $\mathrm{K} / \mathrm{BxN}$ mice on days 0 and 2 , and hind paw thickness was measured bilaterally every day ( $n=5$ per group). On day 11 , hind limbs were fixed and scanned by $\mu$ CT. Histologic sections of the hind paw were also analyzed as in Bone histomorphometry. Inflammation area over total ankle area was determined by measuring inflammatory tissue area on $\mathrm{H} \& \mathrm{E}$ staining of ankle tissue. TRAP ${ }^{+}$area over total tissue area, OC number, and OC surface per bone surface were measured by Bioquant Osteo software (Bioquant Image Analysis Corp.) on TRAP-stained slices of ankle tissue.

Image acquisition. Images of cells and isolated tibial, femoral, and calcaneal bones were taken with a Nikon Eclipse TE300 inverted microscope connected to a Magnafire camera model 599802 (Optronics). The $\times 4$ Nikon lens with numerical aperture 0.13 , the $\times 10$ Nikon lens with numerical aperture 0.30 , or the $\times 40$ Nikon lens with numerical aperture 0.60 was used.

Bone histomorphometry. Mouse hind limbs or tibias/femurs were fixed in $10 \%$ formalin for 24 hours and decalcified in 14\% EDTA solution for 2 weeks (tibia and femur) or 3 weeks (hind limbs with soft tissue). Paraffinembedded sections were stained with $\mathrm{H} \& \mathrm{E}$ for $\mathrm{OB}$ parameter analysis or stained with TRAP for OC parameter analysis within the primary and secondary spongiosa. Sections were analyzed by a blinded operator according to a standard protocol using Bioquant Osteo V7 10.10 (Bioquant Image Analysis Corp.).

Tumor and bone metastasis models. The B16-F10 C57BL/6 murine melanoma cell line (ATCC) was modified to express firefly luciferase (B16-FL) as described (77). For intratibial injections, $1 \times 10^{4} \mathrm{~B} 16$-FL cells in $50 \mu \mathrm{lPBS}$ were injected into the right tibia, and PBS $(50 \mu \mathrm{l})$ was injected into the left tibia as an internal control (77). At day 9, tibias were fixed and decalcified for histologic sections.

For intracardiac injections, the left ventricular chambers of 6-weekold female Balb/c mice were inoculated with $10^{5} 4 \mathrm{~T} 1 \mathrm{BALB} / \mathrm{c}$ triplenegative murine breast cancer cells labeled with GFP-firefly luciferase gene (4T1-GFP-FL) (78) in $50 \mu \mathrm{l}$ PBS as previously described (77). BLI was performed on days $2,7,9$, and 11 after inoculation. Treatment with clopidogrel (30 mg/kg/d in drinking water) was begun 2 days after tumor cell injection. Mice underwent blinded necropsy on day 11 after tumor cell injection, and tibias were fixed and analyzed by $\mu$ CT. Mice were discarded from the final analysis when the animal died before day 11 or necropsy showed a large mediastinal tumor indicative of injection of tumor cells into the chest cavity. In order to have sufficient remaining trabecular bone for histomorphometry analysis, all data were analyzed from the tibia where areas of non-tumor-invaded bone were still present, since tumor burden is often higher in femurs, likely due to increased marrow space.

$B L I$. For BLI of live animals, previously described mice were injected intraperitoneally with $150 \mu \mathrm{g} / \mathrm{g}$ D-luciferin (Biosynth) in PBS, anesthetized with $2.5 \%$ isoflurane, and imaged with a charge-coupled device (CCD) camera-based BLI system (IVIS 100; Caliper; exposure time 1-60 seconds, binning 8 , field of view 12 , f/stop 1 , open filter, anterior side). Signal was displayed as photons $/ \mathrm{s} / \mathrm{cm}^{2} / \mathrm{sr}$ (79). Regions of interest (ROI) were defined manually around the legs using Living Image and IgorPro Software (Version 2.50).

OVX. OVX or sham surgeries were performed as described in ref. 80 with the following modifications: 14 -week-old female C57BL/ 6 mice or $P 2 r y 12^{-/-}$mice were anesthetized using $2 \%$ isoflurane; ovaries were exposed through an abdominal approach and removed by cauterization. The peritoneum and skin were sutured separately. Pain was managed by subcutaneous injection of $0.075 \mathrm{mg} / \mathrm{kg}$ bupernorphine followed by 1:30 dilution of children's liquid pain reliever ( $32 \mathrm{mg}$ acetaminophen $/ \mathrm{ml}$ ) in the drinking water for 2 days. Clopidogrel treatment $(30 \mathrm{mg} / \mathrm{kg} / \mathrm{d}$ in drinking water) was begun 2 days after OVX.

Statistics. Data are shown as mean \pm SD unless noted otherwise. All experiments were analyzed using 2-tailed unpaired Student's $t$ test for 2 groups or 1-way ANOVA with Bonferroni's post-hoc test for 3 or more groups by Prism (GraphPad Software). $P<0.05$ was considered significant.

Study approval. The study protocols were approved by the Washington University Animal Studies Committee.

\section{Acknowledgments}

The authors wish to thank Steven Teitelbaum, F. Patrick Ross, Roberta Faccio, Haibo Zhao, Thomas Baranski, Michael Tomasson, Tiffany Foulks, and Viviana Cremasco for their valuable expert suggestions and criticism. We thank Crystal Idleburg for expert histology. We thank the Musculoskeletal Research Center for histology and microCT (NIH AR057235) and the Molecular Imaging Center for Bioluminescence Studies (P50 CA94056). Thank you to the St. Louis Men Against Cancer and the Barnes Jewish Foundation for support. D.H. Floyd, X. Su, A.C. Hirbe, M.C. Eagleton, S. Townsley, J. Xiang, and K.N. Weilbaecher were supported by R01 CA097250; D.H. Floyd and A.C. Hirbe were supported by hematology training grant T32 HL007088; K. Wu was supported by the Howard Hughes Medical Institute (HHMI); and L. Collins, D. Piwnica-Worms, O. Uluckan, and M.A. Hurchla were supported by P50 CA94056. T.H. Steinberg and D. Grabowska were supported by a VA Merit Review Award. A. Hughes and M.J. Rogers were supported by grant 17285 from Arthritis Research UK.

Received for publication November 9, 2011, and accepted in revised form July 26, 2012.

Address correspondence to: Katherine Weilbaecher, Washington University School of Medicine, Division of Oncology, Campus Box 8069, 660 South Euclid Avenue, St. Louis, Missouri 63110, USA. Phone: 314.454.8858; Fax: 314.454.8973; E-mail: kweilbae@ dom.wustl.edu. 
1. Teitelbaum SL. Bone resorption by osteoclasts. Science. 2000;289(5484):1504-1508.

2. Weilbaecher KN, Guise TA, McCauley LK. Cancer to bone: a fatal attraction. Nat Rev Cancer. 2011;11(6):411-425

3. Orriss I, et al. Bone phenotypes of P2 receptor knockout mice. Front Biosci (Schol Ed). 2011;3:1038-1046.

4. Reyes JP, Sims SM, Dixon SJ. P2 receptor expression, signaling and function in osteoclasts. Front Biosci (Schol Ed). 2011;3:1101-1118.

5. Korcok J, Raimundo LN, Du X, Sims SM, Dixon SJ. P2Y6 nucleotide receptors activate NF-kappaB and increase survival of osteoclasts. J Biol Chem. 2005;280(17):16909-16915.

6. Buckley KA, Hipskind RA, Gartland A, Bowler WB, Gallagher JA. Adenosine triphosphate stimulates human osteoclast activity via upregulation of osteoblast-expressed receptor activator of nuclear factor-kappa B ligand. Bone. 2002;31(5):582-590.

7. Orriss IR, et al. Extracellular nucleotides block bone mineralization in vitro: evidence for dual inhibitory mechanisms involving both P2Y2 receptors and pyrophosphate. Endocrinology. 2007;148(9):4208-4216.

8. Hoebertz A, Meghji S, Burnstock G, Arnett TR. Extracellular ADP is a powerful osteolytic agent: evidence for signaling through the P2Y(1) receptor on bone cells. FASEB J. 2001;15(7):1139-1148.

9. Hollopeter G, et al. Identification of the platelet ADP receptor targeted by antithrombotic drugs. Nature. 2001;409(6817):202-207.

10. Andre P, et al. P2Y12 regulates platelet adhesion/ activation, thrombus growth, and thrombus stability in injured arteries. J Clin Invest. 2003; 112(3):398-406.

11. Herbert JM, Savi P. P2Y12, a new platelet ADP receptor, target of clopidogrel. Semin Vasc Med. 2003;3(2):113-122.

12. Bernardi B, et al. The small GTPase Rap1b regulates the cross talk between platelet integrin alpha2beta1 and integrin alphaIIbbeta3. Blood. 2006;107(7):2728-2735.

13. Bertoni A, et al. Relationships between Rap1b, affinity modulation of integrin alpha IIbbeta 3 , and the actin cytoskeleton. J Biol Chem. 2002;277(28):25715-25721.

14. Kamae T, et al. Critical role of ADP interaction with $\mathrm{P} 2 \mathrm{Y} 12$ receptor in the maintenance of alpha(IIb) beta3 activation: association with Rap1B activation. J Thromb Haemost. 2006;4(6):1379-1387.

15. Kim S, Jin J, Kunapuli SP. Akt activation in platelets depends on Gi signaling pathways.J Biol Chem. 2004;279(6):4186-4195.

16. Larson MK, et al. Identification of P2Y12-dependent and -independent mechanisms of glycoprotein VI-mediated Rap1 activation in platelets. Blood. 2003;101(4):1409-1415.

17. Woulfe D, Jiang H, Mortensen R, Yang J, Brass LF. Activation of Rap1B by G(i) family members in platelets. J Biol Chem. 2002;277(26):23382-23390.

18. Lorenowicz MJ, van GJ, de BM, Hordijk PL, Fernandez-Borja M. Epac1-Rap1 signaling regulates monocyte adhesion and chemotaxis. J Lenkoc Biol. 2006;80(6):1542-1552.

19. Lorenowicz MJ, Fernandez-Borja M, Kooistra MR, Bos JL, Hordijk PL. PKA and Epac1 regulate endothelial integrity and migration through parallel and independent pathways. Eur J Cell Biol. 2008;87(10):779-792

20. Medeiros RB, et al. Protein kinase D1 and the beta 1 integrin cytoplasmic domain control beta 1 integrin function via regulation of Rap1 activation. Immunity. 2005;23(2):213-226.

21. Feng X, et al. A Glanzmann's mutation in beta 3 integrin specifically impairs osteoclast function. J Clin Invest. 2001;107(9):1137-1144.

22. Bakewell SJ, et al. Platelet and osteoclast beta3 integrins are critical for bone metastasis. Proc Natl Acad
Sci U S A. 2003;100(24):14205-14210.

23. Faccio R, Novack DV, Zallone A, Ross FP, Teitelbaum SL. Dynamic changes in the osteoclast cytoskeleton in response to growth factors and cell attachment are controlled by beta 3 integrin. $J$ Cell Biol. 2003;162(3):499-509.

24. Ross FP, Teitelbaum SL. alphavbeta3 and macrophage colony-stimulating factor: partners in osteoclast biology. Immunol Rev. 2005;208:88-105

25. Zhao H, Kitaura H, Sands MS, Ross FP, Teitelbaum SL, Novack DV. Critical role of beta3 integrin in experimental postmenopausal osteoporosis. J Bone Miner Res. 2005;20(12):2116-2123.

26. Ohsawa K, Irino Y, Nakamura Y, Akazawa C, Inoue $\mathrm{K}$, Kohsaka S. Involvement of P2X4 and P2Y12 receptors in ATP-induced microglial chemotaxis. Glia. 2007;55(6):604-616.

27. Simon J, et al. Characterization and channel coupling of the $\mathrm{P} 2 \mathrm{Y}(12)$ nucleotide receptor of brain capillary endothelial cells. J Biol Chem. 2002;277(35):31390-31400.

28. Tolhurst G, Vial C, Leon C, Gachet C, Evans RJ, Mahaut-Smith MP. Interplay between P2Y(1), $\mathrm{P} 2 \mathrm{Y}(12)$, and $\mathrm{P} 2 \mathrm{X}(1)$ receptors in the activation of megakaryocyte cation influx currents by ADP: evidence that the primary megakaryocyte represents a fully functional model of platelet $\mathrm{P} 2$ receptor signaling. Blood. 2005;106(5):1644-1651.

29. Krzeminski P, Suplat D, Czajkowski R, Pomorski $\mathrm{P}$, Baranska J. Expression and functional characterization of $\mathrm{P} 2 \mathrm{Y} 1$ and $\mathrm{P} 2 \mathrm{Y} 12$ nucleotide receptors in long-term serum-deprived glioma C6 cells. FEBS J. 2007;274(8):1970-1982

30. Mamedova LK, Gao ZG, Jacobson KA. Regulation of death and survival in astrocytes by ADP activating P2Y1 and P2Y12 receptors. Biochem Pharmacol. 2006;72(8):1031-1041.

31. Haynes SE, et al. The P2Y12 receptor regulates microglial activation by extracellular nucleotides. Nat Neurosci. 2006;9(12):1512-1519.

32. Myrtek D, et al. Activation of human alveolar macrophages via $\mathrm{P} 2$ receptors: coupling to intracellular $\mathrm{Ca} 2+$ increases and cytokine secretion. J Immunol. 2008;181(3):2181-2188

33. Pausch MH, Lai M, Tseng E, Paulsen J, Bates B, Kwak S. Functional expression of human and mouse P2Y12 receptors in Saccharomyces cerevisiae. Biochem Biophys Res Commun. 2004;324(1):171-177.

34. Ravichandran KS. Find-me and eat-me signals in apoptotic cell clearance: progress and conundrums. J Exp Med. 2010;207(9):1807-1817.

35. Junger WG. Immune cell regulation by autocrine purinergic signalling. Nat Rev Immunol. 2011;11(3):201-212.

36. Pellegatti P, Raffaghello L, Bianchi G, Piccardi F, Pistoia V, Di VF. Increased level of extracellular ATP at tumor sites: in vivo imaging with plasma membrane luciferase. PLoS One. 2008;3(7):e2599.

37. Moreira PI, Santos MS, Moreno AM, Seica R, Oliveira CR. Increased vulnerability of brain mitochondria in diabetic (Goto-Kakizaki) rats with aging and amyloid-beta exposure. Diabetes. 2003; 52(6):1449-1456

38. Schroder K, Tschopp J. The inflammasomes. Cell. 2010;140(6):821-832

39. Honda S, et al. Extracellular ATP or ADP induce chemotaxis of cultured microglia through Gi/o-coupled P2Y receptors. J Neurosci. 2001;21(6):1975-1982.

40. Kurpius D, Nolley EP, Dailey ME. Purines induce directed migration and rapid homing of microglia to injured pyramidal neurons in developing hippocampus. Glia. 2007;55(8):873-884

41. Marcinek DJ, Schenkman KA, Ciesielski WA, Lee D, Conley KE. Reduced mitochondrial coupling in vivo alters cellular energetics in aged mouse skeletal muscle. J Physiol. 2005;569(pt 2):467-473.

42. Navarro A, Boveris A. The mitochondrial energy transduction system and the aging process. $A m J$
Physiol Cell Physiol. 2007;292(2):C670-C686.

43. Ryan LM, Rachow JW, McCarty DJ. Synovial fluid ATP: a potential substrate for the production of inorganic pyrophosphate. J Rheumatol. 1991;18(5):716-720.

44. Bodor ET, Waldo GL, Hooks SB, Corbitt J, Boyer JL, Harden TK. Purification and functional reconstitution of the human $\mathrm{P} 2 \mathrm{Y} 12$ receptor. Mol Pharmacol. 2003;64(5):1210-1216.

45. Dorsam RT, Kunapuli SP. Central role of the $\mathrm{P} 2 \mathrm{Y} 12$ receptor in platelet activation. J Clin Invest. 2004;113(3):340-345.

46. Kronlage $\mathrm{M}$, et al. Autocrine purinergic receptor signaling is essential for macrophage chemotaxis. Sci Signal. 2010;3(132):ra55.

47. McHugh KP, et al. Mice lacking beta3 integrins are osteosclerotic because of dysfunctional osteoclasts. J Clin Invest. 2000;105(4):433-440.

48. Falker K, Lange D, Presek P. P2Y12 ADP receptordependent tyrosine phosphorylation of proteins of 27 and $31 \mathrm{kDa}$ in thrombin-stimulated human platelets. Thromb Haemost. 2005;93(5):880-888.

49. Kauffenstein G, et al. The P2Y(12) receptor induces platelet aggregation through weak activation of the alpha(IIb)beta(3) integrin--a phosphoinositide 3-kinase-dependent mechanism. FEBS Lett. 2001;505(2):281-290.

50. Gao L, et al. Ras-associated protein-1 regulates extracellular signal-regulated kinase activation and migration in melanoma cells: two processes important to melanoma tumorigenesis and metastasis. Cancer Res. 2006;66(16):7880-7888.

51. Faccio R, Takeshita S, Zallone A, Ross FP, Teitelbaum SL. c-Fms and the alphavbeta3 integrin collaborate during osteoclast differentiation. J Clin Invest. 2003;111(5):749-758.

52. Bradley EW, Ruan MM, Vrable A, Oursler MJ. Pathway crosstalk between Ras/Raf and PI3K in promotion of M-CSF-induced MEK/ERKmediated osteoclast survival. J Cell Biochem. 2008; 104(4):1439-1451.

53. Korganow AS, et al. From systemic T cell self-reactivity to organ-specific autoimmune disease via immunoglobulins. Immunity. 1999;10(4):451-461.

54. Savi P, et al. The active metabolite of Clopidogrel disrupts P2Y12 receptor oligomers and partitions them out of lipid rafts. Proc Natl Acad Sci U S A. 2006;103(29):11069-11074.

55. Smyth SS, Tsakiris DA, Scudder LE, Coller BS. Structure and function of murine alphaIIbbeta3 (GPIIb/IIIa): studies using monoclonal antibodies and beta3-null mice. Thromb Haemost. 2000;84(6):1103-1108.

56. Novack DV, Teitelbaum SL. The osteoclast: friend or foe? Annu Rev Pathol. 2008;3:457-484.

57. De Simone R, Niturad CE, De Nuccio C, AjmoneCat MA, Visentin S, Minghetti L. TGF-beta and LPS modulate ADP-induced migration of microglial cells through P2Y1 and P2Y12 receptor expression. J Neurochem. 2010;115(2):450-459.

58. Chrzanowska-Wodnicka M, Smyth SS, Schoenwaelder SM, Fischer TH, White GC. Rap1b is required for normal platelet function and hemostasis in mice. J Clin Invest. 2005;115(3):680-687.

59. Chrzanowska-Wodnicka M, Kraus AE, Gale D, White GC, Vansluys J. Defective angiogenesis, endothelial migration, proliferation, and MAPK signaling in Rap1b-deficient mice. Blood. 2008; 111(5):2647-2656.

60. Dorsam RT, Kim S, Jin J, Kunapuli SP. Coordinated signaling through both $\mathrm{G} 12 / 13$ and $\mathrm{G}(\mathrm{i})$ pathways is sufficient to activate GPIIb/IIIa in human platelets. J Biol Chem. 2002;277(49):47588-47595.

61. Irino Y, Nakamura Y, Inoue K, Kohsaka S, Ohsawa $\mathrm{K}$. Akt activation is involved in $\mathrm{P} 2 \mathrm{Y} 12$ receptormediated chemotaxis of microglia. J Neurosci Res. 2008;86(7):1511-1519.

62. Jantzen HM, Milstone DS, Gousset L, Con- 
ley PB, Mortensen RM. Impaired activation of murine platelets lacking $\mathrm{G}$ alpha(i2). J Clin Invest. 2001;108(3):477-483.

63. Itzstein C, Coxon FP, Rogers MJ. The regulation of osteoclast function and bone resorption by small GTPases. Small GTPases. 2011;2(3):117-130.

64. Ito $\mathrm{Y}$, et al. $\mathrm{Cdc} 42$ regulates bone modeling and remodeling in mice by modulating RANKL/M-CSF signaling and osteoclast polarization. J Clin Invest. 2010;120(6):1981-1993.

65. Iyu D, et al. Mode of action of P2Y(12) antagonists as inhibitors of platelet function. Thromb Haemost 2011;105(1):96-106.

66. Jackson SW, et al. Disordered purinergic signaling inhibits pathological angiogenesis in cd39/Entpd1-null mice. Am J Pathol. 2007;171(4):1395-1404.

67. Uluckan O, et al. APT102, a novel adpase, cooperates with aspirin to disrupt bone metastasis in mice. J Cell Biochem. 2008;104(4):1311-1323.

68. Winning J, Claus RA, Pletz MW, Bauer M, Losche W. Adenosine diphosphate receptor antagonist clopidogrel sulfate attenuates LPS-induced sys- temic inflammation in a rat model. Shock. 2011; 36(3):317-318.

69. Reynolds LE, et al. Enhanced pathological angiogenesis in mice lacking beta 3 integrin or beta 3 and beta5 integrins. Nat Med. 2002;8(1):27-34.

70. Robinson SD, Hodivala-Dilke KM. The role of beta3-integrins in tumor angiogenesis: context is everything. Curr Opin Cell Biol. 2011;23(5):630-637.

71. Suva LJ, et al. Platelet dysfunction and a high bone mass phenotype in a murine model of platelet-type von Willebrand disease. Am J Pathol. 2008;172(2):430-439.

72. Morgan EA, et al. Dissection of platelet and myeloid cell defects by conditional targeting of the beta3integrin subunit. FASEB J. 2010;24(4):1117-1127.

73. Vestergaard P, Steinberg TH, Schwarz P, Jørgensen NR. Use of the oral platelet inhibitors dipyridamole and acetylsalicylic acid is associated with increased risk of fracture [published online ahead of print April 2, 2011]. Int J Cardiol. doi:10.1016/ j.ijcard.2011.03.026.

74. Michelson AD. New P2Y12 antagonists. Curr Opin
Hematol. 2009;16(5):371-377.

75. Hodivala-Dilke KM, et al. Beta3-integrin-deficient mice are a model for Glanzmann thrombasthenia showing placental defects and reduced survival. J Clin Invest. 1999;103(2):229-238.

76. Léon C, et al. Defective platelet aggregation and increased resistance to thrombosis in purinergic P2Y(1) receptor-null mice. J Clin Invest. 1999;104(12):1731-1737.

77. Uluckan O, et al. CD47 regulates bone mass and tumor metastasis to bone. Cancer Res. 2009; 69(7):3196-3204

78. Smith MC, et al. CXCR4 regulates growth of both primary and metastatic breast cancer. Cancer Res. 2004;64(23):8604-8612.

79. Gross S, Piwnica-Worms D. Real-time imaging of ligand-induced IKK activation in intact cells and in living mice. Nat Methods. 2005;2(8):607-614.

80. Lai CF, et al. Accentuated ovariectomy-induced bone loss and altered osteogenesis in heterozygous N-cadherin null mice. J Bone Miner Res. 2006; 21(12):1897-1906. 